\title{
The Economic Costs of Type 2 Diabetes: A Global Systematic Review
}

\author{
Till Seuring $\cdot$ Olga Archangelidi $\cdot$ Marc Suhrcke
}

Published online: 19 March 2015

(C) The Author(s) 2015. This article is published with open access at Springerlink.com

\begin{abstract}
Background There has been a widely documented and recognized increase in diabetes prevalence, not only in high-income countries (HICs) but also in low- and middleincome countries (LMICs), over recent decades. The economic burden associated with diabetes, especially in LMICs, is less clear.

Objective We provide a systematic review of the global evidence on the costs of type 2 diabetes. Our review seeks to update and considerably expand the previous major review of the costs of diabetes by capturing the evidence on overall, direct and indirect costs of type 2 diabetes worldwide that has been published since 2001. In addition, we include a body of economic evidence that has hitherto been distinct from the cost-of-illness (COI) work, i.e. studies on the labour market impact of diabetes.

Methods We searched PubMed, EMBASE, EconLit and IBSS (without language restrictions) for studies assessing
\end{abstract}

Electronic supplementary material The online version of this article (doi:10.1007/s40273-015-0268-9) contains supplementary material, which is available to authorized users.

\section{T. Seuring $(\bowtie) \cdot$ M. Suhrcke}

Health Economics Group, Norwich Medical School, University of East Anglia, Norwich, UK

e-mail: T.Seuring@uea.ac.uk

\section{O. Archangelidi}

Clinical Epidemiology Group, Department of Epidemiology and Public Health, University College London, London, UK

\section{Suhrcke}

Centre for Health Economics, University of York, York, UK

M. Suhrcke

UKCRC Centre for Diet and Activity Research (CEDAR),

Cambridge, UK the economic burden of type 2 diabetes published from January 2001 to October 2014. Costs reported in the included studies were converted to international dollars (\$) adjusted for 2011 values. Alongside the narrative synthesis and methodological review of the studies, we conduct an exploratory linear regression analysis, examining the factors behind the considerable heterogeneity in existing cost estimates between and within countries.

Results We identified $86 \mathrm{COI}$ and 23 labour market studies. COI studies varied considerably both in methods and in cost estimates, with most studies not using a control group, though the use of either regression analysis or matching has increased. Direct costs were generally found to be higher than indirect costs. Direct costs ranged from $\$ 242$ for a study on out-of-pocket expenditures in Mexico to $\$ 11,917$ for a study on the cost of diabetes in the USA, while indirect costs ranged from $\$ 45$ for Pakistan to $\$ 16,914$ for the Bahamas. In LMICs-in stark contrast to HICs - a substantial part of the cost burden was attributed to patients via out-of-pocket treatment costs. Our regression analysis revealed that direct diabetes costs are closely and positively associated with a country's gross domestic product (GDP) per capita, and that the USA stood out as having particularly high costs, even after controlling for GDP per capita. Studies on the labour market impact of diabetes were almost exclusively confined to HICs and found strong adverse effects, particularly for male employment chances. Many of these studies also took into account the possible endogeneity of diabetes, which was not the case for COI studies.

Conclusions The reviewed studies indicate a large economic burden of diabetes, most directly affecting patients in LMICs. The magnitude of the cost estimates differs considerably between and within countries, calling for the contextualization of the study results. Scope remains large for 
adding to the evidence base on labour market effects of diabetes in LMICs. Further, there is a need for future COI studies to incorporate more advanced statistical methods in their analysis to account for possible biases in the estimated costs.

\section{Key Points for Decision Makers}

The evidence documenting the large-and at least partly avoidable-economic burden of type 2 diabetes has grown rapidly in the past 13 years.

Many studies documenting the economic costs of type 2 diabetes in low- and middle-income countries (LMICs) have emerged, providing a first picture of the economic impact of diabetes in poorer countries, whereas the evidence on the labour market effects in LMICs remains scarce.

Costs of diabetes, as well as its adverse labour market effects, increase over time and with disease severity, indicating that early investments into prevention and disease management may be particularly worthwhile.

COI studies in particular did not rigorously account for potential biases in their estimation, suggesting that cost-effectiveness studies that make use of these estimates might under- or overestimate the value for money of the respective intervention or drug.

\section{Introduction}

Diabetes is a chronic disease that has spread widely, not only in high-income countries (HICs) but also in many low- and middle-income countries (LMICs) over recent decades. The most recent data from the International Diabetes Federation (IDF) indicate that diabetes affected 382 million people worldwide in 2013, a number that is expected to grow to 592 million by 2035 . The estimated global prevalence in 2013 amounts to $8.3 \%$ among people aged 20-79 years, with the world's most populous countries, India and China, reaching prevalence rates between 9 and $10 \%$, corresponding to 65 and 100 million in absolute numbers, respectively. Particularly high prevalence rates are found in Mexico (12.6\%) and Egypt (16.8\%), surpassing the rates of most HICs, including the USA (9.2\%) and Germany (8.2\%) [1]. Taken together, in 2013 about two-thirds of all individuals with diabetes lived in LMICs [1]. The rising prevalence of diabetes in LMICs appears to be fuelled by rapid urbanization, nutrition transition and increasingly sedentary lifestyles [2]. The most prevalent form of diabetes by far is type 2 diabetes, affecting about $90 \%$ of people with diabetes, while the remaining $10 \%$ mainly have type 1 diabetes or gestational diabetes [1].

Due to its adverse effect on people's health, diabetes also imposes an economic burden on individuals and households affected as well as on healthcare systems. The economic burden of diabetes was confirmed by Ettaro et al. [3] in a review of cost-of-illness (COI) studies on diabetes mellitus, published in 2004, covering the literature up to the year 2000. The authors concluded that the direct and indirect economic burden of diabetes was "large", and that costs had increased over time. However, the review also noted that significant variation in costing methodologies made it near impossible to directly compare the cost estimates. However, the studies reviewed by Ettaro et al. [3] were almost exclusively focused on the USA, with a small number coming from European HICs and none from LMICs. The aim of this study is therefore to systematically review the literature on the economic costs of diabetes published since 2001 (i.e. the first year not covered by the Ettaro et al. [3] review), as we expect a considerable number of new studies, also from LMICs. In addition to the COI studies, we review the literature on labour market outcomes, with a specific interest in the methodological challenges involved. In doing so, we substantively update and expand the scope of the Ettaro et al. [3] review, allowing us to revisit its findings regarding the evidence base about the economic burden of type 2 diabetes globally.

COI studies generally assess the direct and indirect costs of a particular illness, where the former represent the opportunity cost of resources used for treatment. The indirect costs measure the value of resources lost due the illness, most commonly those caused by losses in productivity due to mortality and morbidity as measured in lost earnings [4]. In addition, another approach also focuses on estimating the impact of diabetes on labour market outcomes. However, rather than trying to estimate the monetary losses that arise from a decrease in productivity, these studies typically compare labour market outcomes (e.g. employment probabilities, earnings or lost work days) between people with and without diabetes, while accounting for differences in age, education and other demographic and socioeconomic variables, that might arise between both groups and that could affect labour market outcomes as well as the chances of developing diabetes. The aim of studies in this field is to obtain a clearer picture of how diabetes causally affects these labour market outcomes, without necessarily monetizing the results. Because of the different methodologies and data requirements, these studies tend to differ considerably from traditional COI studies, which is why we reviewed them separately. To the best of our knowledge, this is the first review that systematically assesses the studies in this particular field. 


\section{Methods}

PRISMA (Preferred Reporting Items for Systematic Reviews and Meta-Analyses) guidelines were used as a basis for the overall study approach [5].

\subsection{Search Strategy}

The electronic search was based on the following search terms: 'Diabetes Mellitus' [Mesh] AND ('Costs and Cost Analysis' [Mesh] OR 'Cost of Illness' [Mesh] OR 'Employment' [Mesh] OR 'Labor Market' [All fields] OR 'Labour Market' [All fields] OR 'Productivity' OR 'Willingness to pay' [All fields]). The above search was run in PubMed and was then adapted for searches in EMBASE, EconLit and the International Bibliography of the Social Sciences (IBSS). The search was carried out from October 2012 to October 2014 and restricted to studies published between January 2001 and October 2014, as the earlier review had covered COI studies until 2000 [3]. No language restrictions were applied. The references were downloaded in RIS format where possible and then transferred to Mendeley. Authors were contacted for further information if clarification was needed after the fulltext analysis.

\subsection{Inclusion and Exclusion Criteria}

Studies were eligible if a monetary estimate of the direct and/or indirect costs of diabetes was presented in the results section or if studies provided an estimate of the impact of diabetes on labour market outcomes (employment chances, labour income, wages and lost work days). We did not exclude studies with a small sample size, as this might have discriminated against studies in LMICs. Studies on types of diabetes explicitly different from type 2 diabetes were excluded. However, we included studies that did not explicitly mention the type of diabetes, given that type 2 diabetes accounts for about $90 \%$ of all diabetes cases. Studies exclusively assessing the costs of diabetes complications or the costs of management strategies were excluded as were studies estimating the costs for specific groups with diabetes (e.g. costs for people with poorly controlled diabetes), since we were interested in the costs incurred to populations comprising the whole spectrum of people with type 2 diabetes. Editorials and reviews and studies for which the full text could not be retrieved or only an abstract was available were also excluded.

\subsection{Data Extraction and Analysis}

Data extraction was carried out by two investigators (TS and OA). After duplicates were removed, titles and abstracts were scanned by one researcher (TS) to identify studies suitable for a full-text review. The process was checked by a second researcher (OA) on a random subsample of 2,000 studies of the retrieved references. The full text was subsequently retrieved for the identified studies, and they were reviewed by two researchers (TS and OA), with disagreements resolved by discussion. Finally, 109 studies were identified (see Fig. 1) that fulfilled the inclusion criteria, and data extraction was carried out using a pre-defined extraction table. Primary outcomes were the total costs, the direct costs, and the indirect costs of type 2 diabetes and the respective per capita estimates of these outcomes, as well as the impact of type 2 diabetes on employment chances, income, wages and lost work days. Secondary outcomes comprised the methodology used to assess the monetary costs of type 2 diabetes, the range of cost factors included in the analysis, as well as the methodology used to assess the labour market impact of diabetes. Further extracted information included the year of publication, year of data collection, the time horizon, the country or region studied, the data source, sample size and age as well as information on whether the study distinguished between types of diabetes.

We present the COI study results in per capita values to facilitate comparability across countries. For studies presenting overall population level estimates rather than per capita costs information, we calculated those costs, whenever possible, using the diabetes prevalence mentioned in the respective study. If no total cost estimate was presented but information on direct and indirect costs was available, then direct and indirect costs were added up to produce a total cost estimate. We converted costs into purchasing power parity (PPP) adjusted estimates, also called international dollars and henceforth denoted with the $\$$ sign, in order to further increase comparability. Since some studies did not present the data in the country's local currency but in US\$ or some other major currency, we used the exchange rate given in the article to convert the estimates back into the local currency. If no exchange rate was provided in the study itself, we used the average exchange rate (midpoint exchange rate according to OANDA historical exchange rates [http://www.oanda.com/currency/ historical-rates/]) for the reported year. The PPP-adjusted estimates for the year 2011 were then calculated using the Campbell and Cochrane Economics Methods Group Evidence for Policy and Practice Information and Coordination Centre (CCEMG-EEPPI Centre) cost converter [6]. For all additional analyses carried out in the following sections, only studies for which a mean cost estimate was presented or could be calculated were included. Further, in the case of a study presenting estimates for more than 1 year, only the estimate for the most recent year was used for the analysis. For studies presenting both incremental 
Fig. 1 PRISMA [5] flowchart. COI cost of illness, PRISMA Preferred Reporting Items for Systematic Reviews and MetaAnalyses

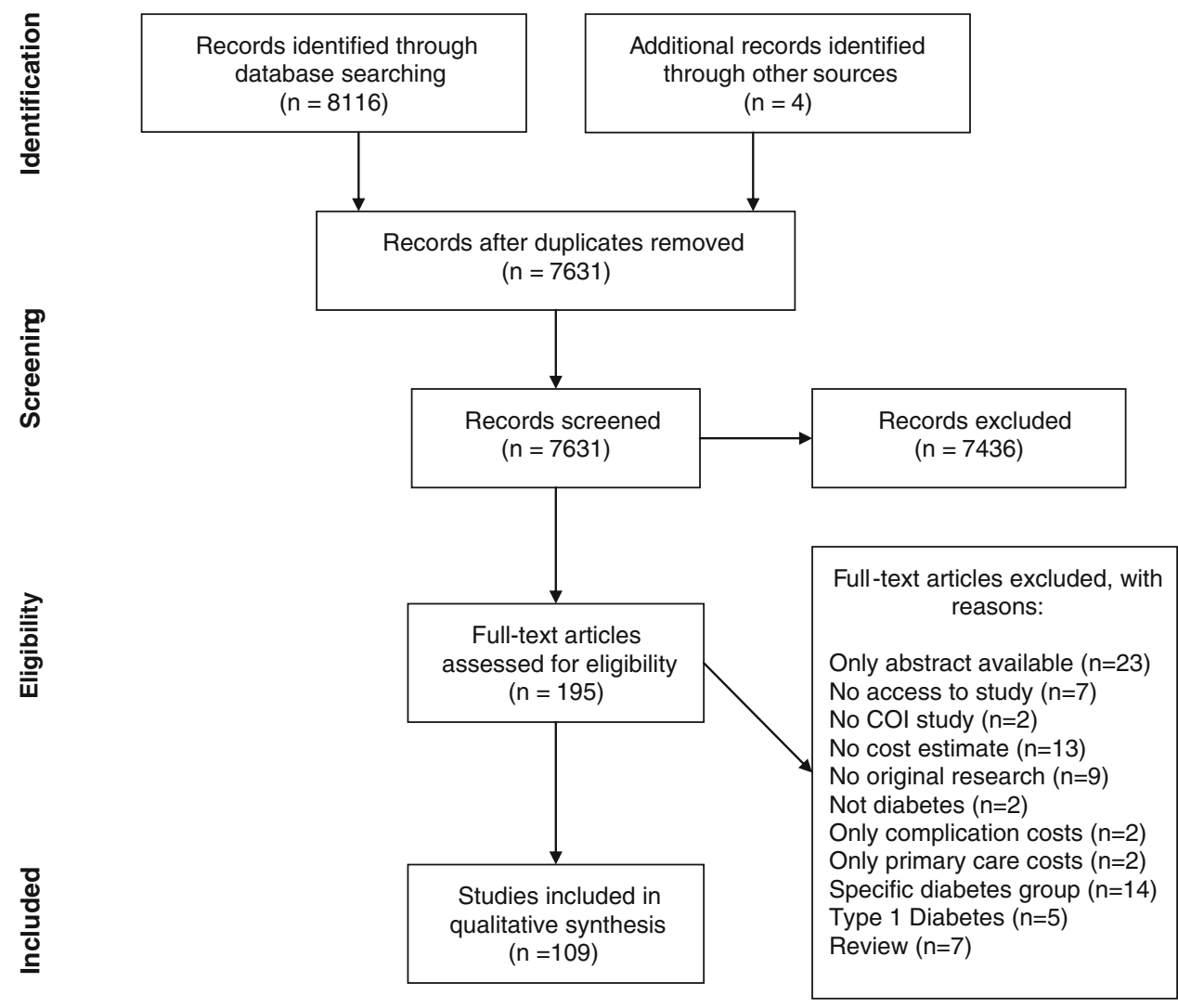

complications into account. The year of the used data was considered because the development of social security systems and treatment methods may affect how the direct costs evolve over time. We categorized this variable into groups: studies using data from before 1995, 1995-1999, 2000-2004, 2005-2009 and 2010-2014. The dummy variable for studies on the USA was included to account for the generally higher healthcare expenditures in the USA compared with other HICs with similar per capita income levels [8]. Accounting for national representativeness should cancel out any effects that might be driven by those studies that estimate costs for sub-national-, regional- or city-level population samples. Including an estimator for diabetes complications should account for the possible underestimation of diabetes costs in studies excluding complications. We exclude country estimates extracted from multi-country studies in our preferred specification, as their inclusion would lead to an over-statement of the cost effect of the estimation method employed in the given multi-country study.

\section{Results}

Due to the differences in methodologies, we first present the findings on the identified COI studies and subsequently turn to studies on labour market outcomes. 
3.1 Cost-of-Illness (COI) Studies on Type 2 Diabetes

\subsubsection{Number of Studies}

We identified a total of 86 relevant COI studies (see Table EMS_1 in the Electronic Supplementary Material [EMS] 1 for a detailed description of the included studies), of which 62 focused on HICs, 23 on LMICs, and one multi-country study covered both HICs and LMICs. Studies on LMICs increased over time, with the majority of the LMIC studies being published between 2007 and 2014. Six of the selected studies were multi-country studies, of which two [9, 10] did not provide detailed cost estimates for every country in the study and one did not provide a year for the estimated costs, so that we could not calculate estimates in international dollars [11]. Therefore, we could not include these particular studies in our country-specific analysis.

\subsubsection{Regional Distribution}

In terms of geographic regions, most studies were carried out on countries in Latin America and the Caribbean $(n=38)$ and Europe $(n=37)$, followed by the USA and Canada $(n=26)$, East Asia and Pacific $(n=11)$, the Middle East and North Africa $(n=5)$, South Asia $(n=4)$, Sub-Saharan Africa $(n=4)$ and Australia $(n=1) .{ }^{1}$ The USA was the most studied country $(n=19)$, followed by Canada $(n=7)$ and Germany $(n=5)$. Mexico $(n=6)$ and China $(n=4)$ were the most frequently studied LMICs.

\subsubsection{Data Sources}

Especially in LMICs, self-administered surveys represented a popular method to retrieve data on the cost of diabetes. These were mostly limited regionally, i.e. to a city or hospital, and usually only representative of these regional diabetes populations but not of a national population. In HICs, databases of insurance and healthcare providers were the main source of information in most studies. These data tended to be representative, either at a national or at some sub-national level. As a result, the size of the samples in HICs was mostly between 1,000 and several million. By contrast, studies in low- and lower-middle-income countries were generally characterized by smaller sample sizes, ranging from 35 [12] to about 2,433 [13] in the studies reviewed here.

\footnotetext{
1 The number of countries studied is higher than the number of articles reviewed due to four multi-country studies estimating costs for multiple countries $[11,14,15,41]$.
}

\subsubsection{Variation in Costing Approaches}

As discussed in more detail in the Text Box in ESM 2, a range of costing approaches can be found in the COI literature. Figure 2 shows that the most common costing method for the direct costs of diabetes in HICs was the sum-all medical approach for people with diabetes without using control groups [9, 11, 14-40]. The disease-attributable costing approach $[12,41-54]$ and the attributable-fraction approach was also used widely, although mainly in the USA [55-61]. The incremental cost approach was applied primarily in studies on HICs [10, 13, $51,60,62-79]$. For LMICs, the survey approach was the most used [80-92].

By contrast, almost all indirect cost assessments followed the same methodology, i.e. the human capital approach. This approach considers all forgone labour earnings of a patient or caregiver that are attributable to diabetes. A minority of three studies [91, 93, 94] estimated the indirect costs using the willingness-to-pay (WTP) approach, which tries to measure how much individuals would be willing to pay to reduce the risk of an illness [4], here diabetes (or certain complications associated with it). One of the studies included WTP estimates in addition to the direct and indirect costs measured by the human capital approach [91] but did not include the WTP estimate in the

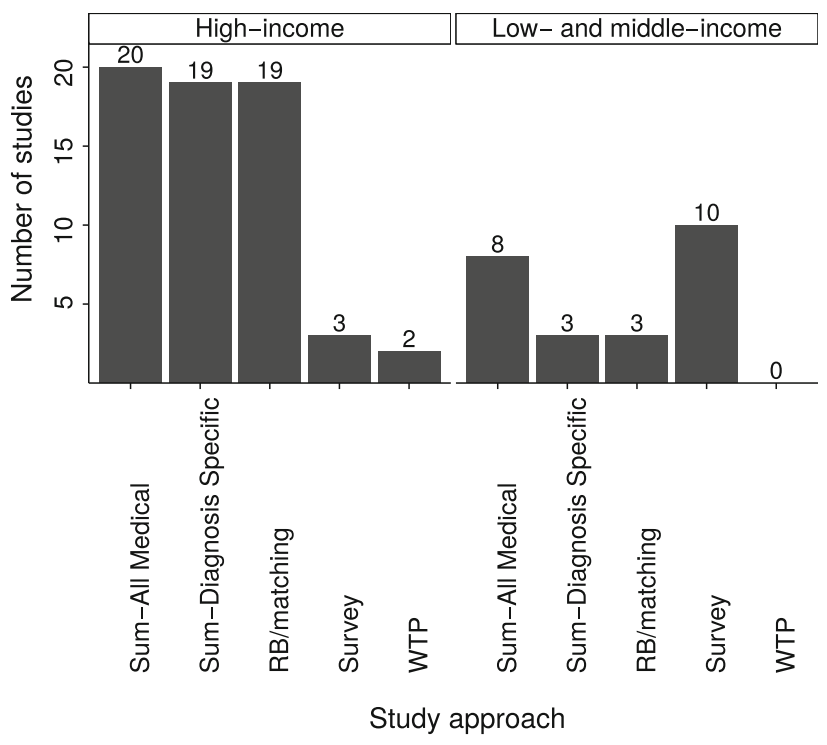

Fig. 2 Number of cost-of-illness studies, by costing approach and income group. For LMICs, no WTP study is counted, because the only study [91] presenting a WTP estimate for an LMIC used primarily a different approach to estimate costs, and the WTP estimate was only presented additionally. Therefore, this study was not counted under WTP here. Two studies are counted twice as they give estimates for a sum-diagnosis specific and a $\mathrm{RB} /$ matching approach. LMIC low- to middle-income country, $R B$ regression based, WTP willingness to pay 
overall cost estimate, while the other two studies estimated exclusively the WTP $[93,94]$.

\subsubsection{Study Perspective}

Studies also varied in their perspective, again compromising direct comparability of the cost estimates across studies. Overall, most studies either took a societal $(n=32)$ or healthcare system perspective $(n=48)$. The former generally takes into account the direct and indirect monetary costs that arise to society, including costs to the healthcare system, costs due to lost productivity and sometimes out-of-pocket (OOP) costs [4]. The latter was especially common in HICs, where many studies assessed the cost of diabetes to private or public health insurances. In LMICs, studies often took the patient perspective $(n=$ $5)$, estimating OOP expenditures and in some cases productivity losses, directly arising to the diabetes patient.

\subsubsection{Costing Components}

Of the 75 studies that reported the cost components they used to estimate direct costs, 72 took into account outpatient hospital visits, 70 inpatient hospital visits, 63 physician visits, 58 drug costs, 51 laboratory costs for diagnostic tests and check-ups, 37 equipment costs and 21 non-medical and transportation costs. A total of 46 studies had at least included the costs of hospital, outpatient and physician visits as well as drugs (see Table EMS_3 in ESM 3 for a detailed description of cost components used in each study).

\subsubsection{Cost Estimates of Diabetes Using a Prevalence Approach}

Two basic epidemiological approaches exist for the estimation of COI, and they are not directly comparable. The incidence approach follows people with diabetes, usually starting with their diagnosis at a common base year, estimating yearly costs for a sample of people at the same disease stage, finally giving an estimate of diabetes costs over a certain time period, such as from diagnosis to death or over a distinct period of, for example, 10 years. This approach can also document how costs of diabetes change and develop over the progression of the disease [96]. By contrast, the prevalence approach estimates the costs of diabetes for a cross-section of people with diabetes at a certain point in time, normally a year, who are at different stages of the disease. It is most suitable for assessing the total economic burden of diabetes at a certain point in time. Due to this difference in time periods and the used data, the estimates of prevalence-based studies are not directly comparable with those of incidence-based studies. Hence, we present the cost estimates separately, starting with the prevalence approach.

Table 1 shows the range of direct cost estimates by estimation approach and income status. As can be observed, direct cost estimates varied widely, both between and within the different estimation approaches. Cost estimates for direct costs, irrespective of the costing method applied and the cost components included, ranged from $\$ 242$ for Mexico [28] in 2010 to $\$ 11,917$ for the USA [36] in 2007. Also, studies from LMICs generally indicated smaller direct costs than studies from HICs.

For indirect costs, studies using the human capital approach estimated costs ranging from $\$ 45$ for Pakistan [85] in 2006 to $\$ 16,914$ for the Bahamas [14] in 2000. Three studies estimated indirect costs by using the WTP approach and found costs ranging from $\$ 191$ in a study on the WTP for health insurance for type 2 diabetes in Denmark in 1993 [94], a WTP \$4,004 per year for a cure of type 2 diabetes [93] in Taiwan and an annual payment of $\$ 4,737$ to halt disease progression/prevent future complications of diabetes in India [91].

Societal costs of type 2 diabetes, which are estimated by studies combining direct and indirect costs, ranged from $\$ 544$ in a study on the economic costs of diabetes in Iran [67] in 2001 to $\$ 18,224$ for the Bahamas [14] in 2000.

In order to improve the cross-country comparability of the costs of diabetes, we plotted the results from studies providing a direct per capita cost estimate against the GDP per capita estimate of the respective country (we limited this comparison to studies using samples representative of their entire population). Figure 3 confirms the expectation that costs do increase with economic wealth: GDP per capita explains about one-third of the variation in cost estimates (see $r^{2}$ in Fig. 3). Also, studies on the USA seem to estimate costs consistently higher than would be expected on the basis of its GDP per capita.

Again, the wide variation in estimated costs for many countries underscores the point that the studies need to be contextualized and may not be directly comparable per se. On the whole - though by no means always - the matching and regression as well as the sum-diagnosis specific approaches appear to produce lower cost estimates than especially the total cost results, particularly so for HICs. In an inevitably crude attempt to quantitatively explore the driving factors behind the heterogeneity in cost estimates, we estimated a simple linear regression model with per capita direct costs as the dependent variable; explanatory variables included GDP per capita, the estimation approach employed by the study, the number of included cost components, a dummy for studies carried out in the USA, the year of data collection, the representativeness of the 
Table 1 Summary of direct costs by estimation approach and income status in international dollars \$ (2011) for prevalence-based studies

\begin{tabular}{|c|c|c|c|c|c|c|c|c|}
\hline & \multicolumn{4}{|c|}{ High-income countries } & \multicolumn{4}{|c|}{ Low- and middle-income countries } \\
\hline & $\begin{array}{l}\text { Sum-all medical } \\
\text { costs }\end{array}$ & $\begin{array}{l}\text { Sum-diagnosis } \\
\text { specific }\end{array}$ & $\mathrm{RB} /$ matching & $\begin{array}{l}\text { Own } \\
\text { survey }\end{array}$ & $\begin{array}{l}\text { Sum-all medical } \\
\text { costs }\end{array}$ & $\begin{array}{l}\text { Sum-diagnosis } \\
\text { specific }\end{array}$ & $\mathrm{RB} /$ matching & $\begin{array}{l}\text { Own } \\
\text { survey }\end{array}$ \\
\hline Min & 1,117 & 907 & 264 & 1,495 & 242 & 662 & 443 & 456 \\
\hline Max & 11,917 & 9,346 & 8,306 & 5,585 & 4,129 & 4,672 & 1,136 & 3,401 \\
\hline$N$ & $25^{\mathrm{a}}$ & $19^{\mathrm{a}}$ & 18 & 3 & $27^{\mathrm{a}}$ & $5^{\mathrm{a}}$ & 2 & 10 \\
\hline
\end{tabular}

$R B$ regression based

${ }^{a}$ Includes country estimates from multi-country studies

Fig. 3 GDP to direct costs ratio by estimation approach. The line depicts the best fit based on the linear regression of direct international dollars. Refer to Table 7 for country abbreviations. For better visibility, the $y$-axis presenting per capita direct costs is expressed in log scale. GDP gross domestic product costs on GDP per capita in

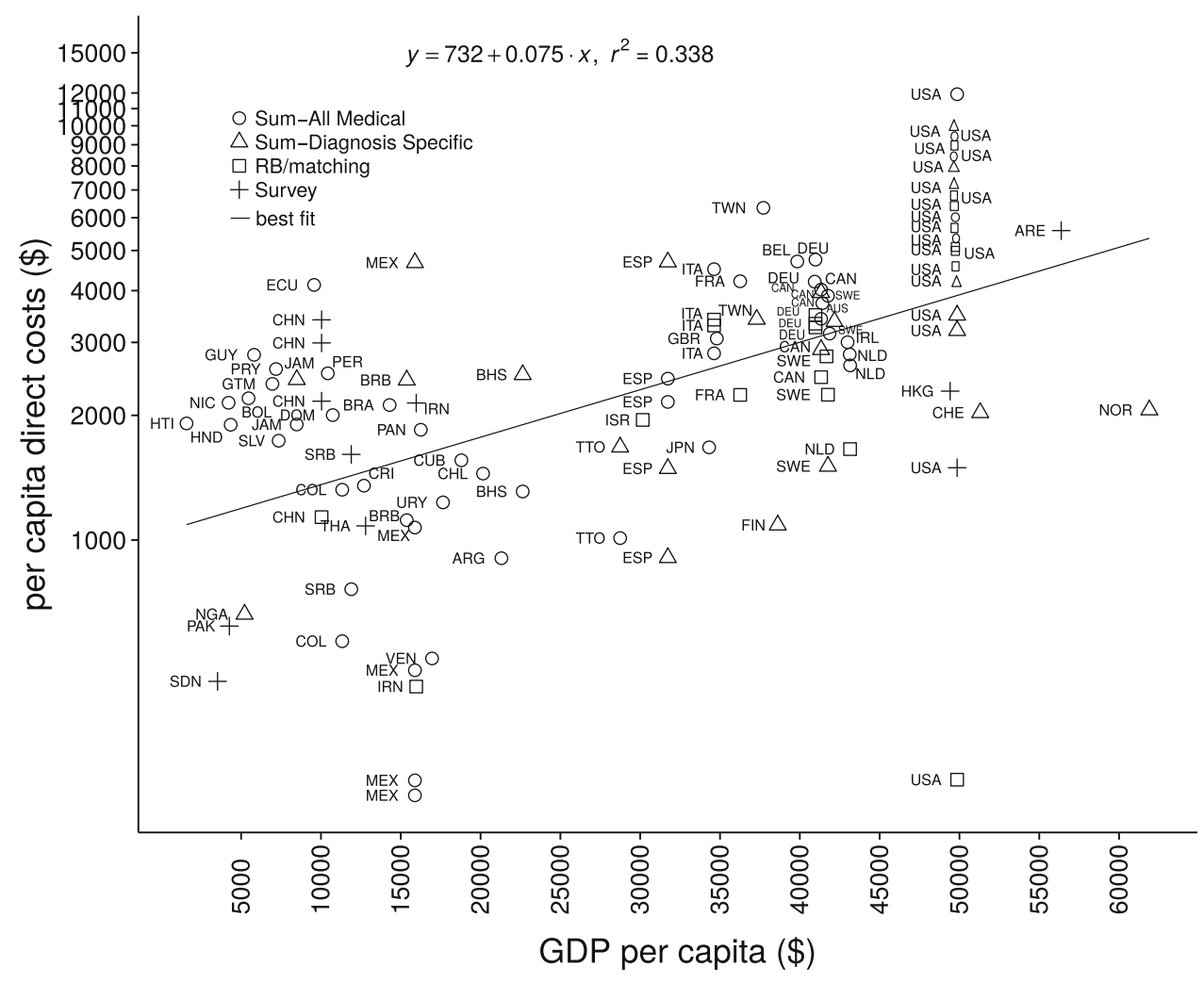

study and whether the study included diabetes complications. The results, displayed in Table 2, show a strong relationship between GDP per capita and expenditures for diabetes, with every additional international dollar in per capita GDP translating into an average increase in direct diabetes expenditures of about $\$ 0.04$. The estimation approach is not found to matter significantly, nor is the year of study. Estimates from USA studies put the costs at over $\$ 3,000$ higher (on average) than studies from other countries, indicating that costs in the USA may indeed be unusually high. The number of costing components and the inclusion of complications likely also explain some of the variance in estimates, although they are just below and above the $10 \%$ significance level, respectively. Overall, the included independent variables explain about $56 \%$ of the variation in direct cost estimates. ${ }^{2}$

The sensitivity of the cost results to the estimation approach was also examined by two studies that investigated the effect of different estimation techniques in diabetes COI studies. Honeycutt et al. [60] compared the use of a regression-based and an attributable-fraction approach and

\footnotetext{
${ }^{2}$ In a sensitivity analysis, we included the results from multi-country studies providing country estimates in the regression analysis. The only major difference to the presented analysis is that the inclusion of complications as well as the number of included cost components were now significant at the 1 and $5 \%$ significance level, respectively. The effect size and significance of the other estimates did not change considerably.
} 
Table 2 Relationship between direct costs and study characteristics (robust linear regression)

\begin{tabular}{llr}
\hline & Estimate & Standard error \\
\hline Constant & 2,133 & 1773.922 \\
GDP per capita (\$) & $0.045^{* *}$ & 0.017 \\
Estimation approach & & \\
$\quad$ Sum-all medical & Ref. & \\
Sum-diagnosis-specific & -413.880 & 528.766 \\
RB/matching & -719.868 & 526.896 \\
Survey & -689.806 & 671.020 \\
At least four costing components & $702.966 *$ & 403.968 \\
USA study & $3,111.067 * * *$ & 533.534 \\
Year of study & & \\
$<1995$ & Ref. & \\
1995-1999 & $-1,744.799$ & 1632.498 \\
2000-2004 & -816.647 & 1586.966 \\
2005-2009 & $-1,021.685$ & 1592.595 \\
2010-2014 & $-2,744.739$ & 1839.689 \\
Study representative & -598.670 & 409.070 \\
Complications & 666.803 & 414.727 \\
$R$-squared adj. & 0.559 & \\
$N$ & 70 & \\
\hline$R e f$. reference category & & \\
\hline
\end{tabular}

Ref. reference category

$* * * p<0.01, * * p<0.05, * p<0.1$

found that the cost estimate of the former exceeded the latter by $43 \%$. Tunceli et al. [51] compared the matching and the diabetes (disease) attributable costs approach and found a 14-29\% higher cost estimate using matching, depending on the used assumptions. Both studies concluded that an incremental cost approach results in a higher, and likely more exact, estimate of the direct costs of diabetes than disease-attributable approaches. The authors attributed this to the fact that a regression or matching approach can assign costs to diabetes that cannot be linked to diabetes otherwise. Those approaches are therefore in a position to account for all costs of co-morbidities caused by diabetes, while this is not automatically the case with the other approaches.

\subsubsection{Direct and Indirect Costs of Diabetes}

To assess the relative importance of direct and indirect costs across countries, we plotted direct against indirect costs from studies that provided both estimates and drew a $45^{\circ}$ line depicting the equal share of direct and indirect costs (see Fig. 4).

Most studies found a larger share for direct costs in comparison with indirect costs (observations above the $45^{\circ}$ line in Fig. 4). This is especially true for HICs, where only a study on Sweden [59] found a larger share for indirect costs. For LMICs, a study on Colombia [19] found considerably higher indirect costs, as did the multi-country study of Barceló et al. [14] and a study on various countries in the African region [9], which both found higher indirect costs for almost every country in the study and also on average for the entire regions, represented as the mean overall study estimate in Fig. 4. Both studies used similar approaches to estimate costs, and indirect cost estimates were likely so high because evidence from only a few countries within the region were used as a basis for estimating indirect costs for every other country in the respective study. Further, the studies took the countries' per capita gross national product as a proxy for earnings, which might have led to an over-estimation of the indirect costs [9].

\subsubsection{Studies Using the Incidence Approach}

The four studies that used an incidence approach (see Table 3) estimated the cost of diabetes either over a person's lifetime $[19,73]$ or over a certain period after diagnosis [21, 52]. González et al. [19] modelled the lifetime (direct and indirect) costs of a typical diabetes patient in Colombia, arriving at a mean cost estimate of $\$ 54,000$. The second study providing lifetime estimates, by Birnbaum et al. [73], estimated incremental lifetime healthcare costs for USA females with diabetes of $\$ 283,000$.

Two studies followed patients over a limited time period and found different patterns in the development of type 2 diabetes-attributable healthcare costs. In Germany, costs increased from $\$ 1,634$ in the first year after diagnosis to $\$ 4,881$ in the 7 th year [21]. In Canada, Johnson et al. [52] found the highest costs in the year of diagnosis, with $\$ 7,635$, up from $\$ 2,755$ the year prior to diagnosis. In the year after diagnosis, costs decreased to $\$ 4,273$ and then only increased slightly to $\$ 4,618$ in year 10 . In Germany and Canada, costs related to complications or hospital visits were the most important components and, in Germany, increased steadily over time. In Canada, costs related to prescriptions increased the most.

\subsubsection{Country-Level Costs Prediction Studies}

Four studies projected costs of diabetes over a certain period of time [16, 17, 42, 80], making assumptions about the future development of diabetes prevalence and population ageing (see Table 4). For Canada, a 1.7-fold increase from 2000 to 2016 [16] and a 2.4-fold increase from 2008 to 2035 in diabetes healthcare costs was estimated [17]. Taking a healthcare system perspective, both studies found 
Fig. 4 Direct and indirect cost relation in studies estimating total costs of type 2 diabetes. The $45^{\circ}$ line depicts the points where direct and indirect costs would be equal. Above the line, direct costs are higher than indirect costs and vice versa. For better visibility, both coordinate axes are expressed in $\log$ scale. Refer to Table 7 for country abbreviations

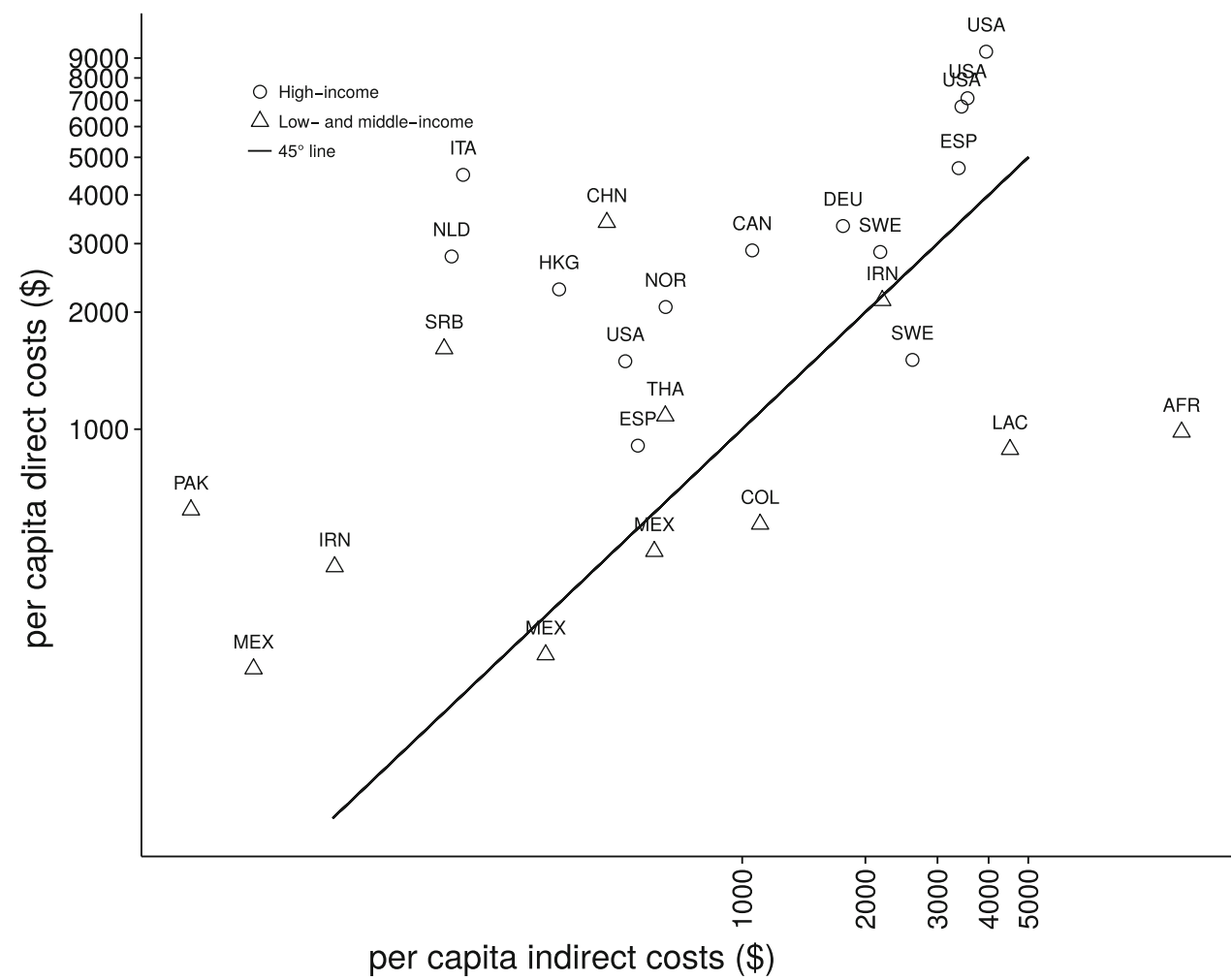

Table 3 Incidence studies on the costs of diabetes

\begin{tabular}{|c|c|c|c|c|c|}
\hline References & Country & $\begin{array}{l}\text { Time } \\
\text { horizon }\end{array}$ & Population & Approach & Results \\
\hline$[52]$ & Canada & 1992-2001 & $\begin{array}{l}\text { Incidence T2D pts from } \\
\text { Saskatchewan Health's } \\
\text { administrative database in Canada }\end{array}$ & $\begin{array}{l}\text { Sum-all } \\
\text { medical }\end{array}$ & $\begin{array}{l}\text { Highest total healthcare costs at year of } \\
\text { diagnosis with CAN } \$ 7,343(\$ 7,635) \text {, then } \\
\text { increased from a low of CANS } \$ 3,880 \text { ( } \$ 4,034) \\
3 \text { years after diagnosis to CAN } \$ 4,441 \text { ten } \\
\text { years thereafter }(\$ 4,618)\end{array}$ \\
\hline [19] & Colombia & 32 years & $\begin{array}{l}\text { Hypothetical average Columbian T2D } \\
\text { pt }\end{array}$ & $\begin{array}{l}\text { Sum-all } \\
\text { medical }\end{array}$ & $\begin{array}{l}\text { Total lifetime costs (32-year period) of average } \\
\text { diabetes pt, including direct and indirect costs, } \\
57.565 \text { million Colombian pesos }(\$ 54,351)\end{array}$ \\
\hline$[21]$ & Germany & 1995-2003 & $\begin{array}{l}\text { Newly diagnosed T2D pts from } \\
\text { randomly drawn practices across } \\
\text { Germany }\end{array}$ & $\begin{array}{l}\text { Sum-all } \\
\text { medical }\end{array}$ & $\begin{array}{l}€ 1,288(\$ 1,635) \text { for the first treatment year after } \\
\text { diabetes diagnosis and increased to } € 3,845 \\
(\$ 4,880) \text { in the } 7 \text { th year }\end{array}$ \\
\hline$[73]$ & USA & 1997-1998 & $\begin{array}{l}\text { Women employed by nationwide } \\
\text { operating company and hypothetical } \\
\text { women above age } 64 \text { receiving } \\
\text { Medicare }\end{array}$ & $\mathrm{RB} /$ matching & $\begin{array}{l}\$ 282,973 \text { incremental lifetime direct healthcare } \\
\text { costs, using incidence-based, steady-state } \\
\text { methodology }\end{array}$ \\
\hline
\end{tabular}

$p t(s)$ patient(s), $R B$ regression based, $T 2 D$ type 2 diabetes

that the estimated increase would be mostly driven by an ageing population. For Australia, Davis et al. [42] estimated a 2.5- to 3.4-fold increase in diabetes-attributable healthcare costs from 2000 to 2051, depending on the underlying assumptions about population ageing and diabetes prevalence rates. For China, Wang et al. [80] extrapolated total costs of diabetes from the year 2007 to 2030, estimating the costs of diabetes to increase 1.8-fold, solely accounting for the expected increase in prevalence.

\subsection{The Impact of Diabetes on Employment Chances and Productivity}

Besides studies that determined the cost of diabetes by costing related expenditures, another body of research has investigated-using econometric techniques-the impact of diabetes on 'productivity', a term used here to comprise outcomes including employment probabilities and lost work days and income or earnings. A recent study 
Table 4 Country-level costs prediction studies

\begin{tabular}{|c|c|c|c|c|c|}
\hline References & Country & Population & Approach & Time horizon & Results \\
\hline$[42]$ & Australia & Australian population & $\begin{array}{l}\text { Sum-diagnosis } \\
\text { specific }\end{array}$ & $2000-2051$ & $\begin{array}{l}\text { If age- and sex-specific prevalence } \\
\text { remains unchanged } \rightarrow 2.5 \text {-fold } \\
\text { increase; if age- and sex-specific } \\
\text { prevalence allowed to change as } \\
\text { well } \rightarrow 3.4 \text {-fold increase }\end{array}$ \\
\hline [16] & Canada & Canadian population & $\begin{array}{l}\text { Sum-all medical } \\
\text { costs }\end{array}$ & 2000-2016 & 1.7-fold increase \\
\hline$[17]$ & Canada & $\begin{array}{l}\text { Four Alberta Health and Wellness } \\
\text { databases }\end{array}$ & $\begin{array}{l}\text { Sum-all medical } \\
\text { costs }\end{array}$ & 2008-2035 & 2.4-fold increase \\
\hline$[80]$ & China & $\begin{array}{l}\text { In patients and outpatients in } 20 \\
\text { hospitals }\end{array}$ & Own survey & $\begin{array}{l}2007 \text { and } 2030 \\
\text { (projection) }\end{array}$ & $\begin{array}{l}\text { Increase from } \$ 73 \text { billion in } 2007 \\
\text { to } \$ 132 \text { billion in } 2030 \text { (1.8-fold } \\
\text { increase) }\end{array}$ \\
\hline
\end{tabular}

systematically reviewed evidence on the impact of diabetes on the ability to work, focusing on studies assessing the impact of diabetes on early retirement, lost work hours, absenteeism and presenteeism [97]. We focused particularly on studies exploring the impact of diabetes on employment probabilities and earnings-both issues that were not covered in the mentioned review - and we took a more detailed look at the empirical challenges posed by the issue of endogeneity (see the Appendix for a more detailed discussion of endogeneity).

Tables 5 and 6 synthesize the relevant information from the 22 identified studies on the effect of diabetes on employment and other labour market outcomes. Almost all studies were conducted on HICs, mainly the USA $(n=13)$ and European countries $(n=4)$. Only one study focused on a LMIC, investigating the effect of diabetes on labour income in China.

\subsubsection{Employment Chances}

Most studies examined the impact of diabetes on employment probability $(n=17)$, applying a range of econometric techniques. These have evolved over time, and more recent studies took into account the possibility that diabetes might be endogenous: it is conceivable that especially personal traits such as motivation and drive could influence the propensity to develop type 2 diabetes as well as a person's job market opportunities. Further, being employed or unemployed could also lead to changes in lifestyles due to changes in income, stress or leisure time, that could themselves affect the chances of developing diabetes [98]. Of the studies that tried to account for this problem [98103], the majority used an instrumental variables (IV) technique. This approach allows for the consistent estimation of the effect of diabetes on employment if a variable can be found that is causally related to diabetes without affecting the employment chances through any other unobserved pathway apart from its effect on diabetes.
In the case of type 2 diabetes, all studies used the family history of diabetes as an IV to exploit the fact that the development of type 2 diabetes is much more likely for individuals whose biological parents have also had diabetes. It is argued that, while controlling for education, age and other observable demographic and socioeconomic factors (e.g. wealth, regional and ethnic differences and the number of children in the household), having a family member with diabetes should not affect the person's employment status or other labour market outcomes, while strongly predicting the onset of type 2 diabetes.

Because IV estimation has worse asymptotic properties than single equation regression results when endogeneity is not an issue, studies tested for the existence of endogeneity to determine which results to rely on for inference [98101]. Interestingly, the reviewed studies found diabetes to be endogenous for either males [100] or females [98, 99], but never for both. Further, the use of an IV sometimes increased the estimated effect [99, 101], whereas in other cases the effect turned insignificant [98, 100]. As a result, no unambiguous conclusions can be drawn as to how endogeneity affects diabetes and whether or not it causes biased estimates. Most of the relevant studies also explored whether accounting for body mass index (BMI) or other diabetes-related chronic conditions would substantially alter the result and found this not to be the case [98, 100, 104].

Overall, studies more commonly found a significant adverse impact of diabetes on males, ranging from no effect in Canada [100] to a $19 \%$ point reduction in Taiwan [101]. Conversely, no effect was found for women in Taiwan [101], Australia [102] or for Mexican Americans in Texas [98]. However, a $45 \%$ decrease in employment chances was observed for women in the USA [99]. Extending the scope and looking at how diabetes duration affected labour market outcomes using panel data from the USA, one study found that the main adverse effect on employment chances materialized within the first 5 years 
Table 5 Studies estimating the relationship between diabetes and employment (2001-2014)

\begin{tabular}{|c|c|c|c|c|c|}
\hline \multirow[t]{2}{*}{ References } & \multirow[t]{2}{*}{ Survey year } & \multirow[t]{2}{*}{ Country } & \multirow{2}{*}{$\begin{array}{l}\text { Age } \\
\text { (years) }\end{array}$} & \multicolumn{2}{|l|}{ Effect on employment } \\
\hline & & & & Males & Females \\
\hline [103] & 1999-2000 & Australia & $>24$ & $\begin{array}{l}\text { Exogenous: } 10.8 \% \text { point reduction } \\
\text { to be in labour force; endogenous: } \\
7.1 \% \text { points reduction; test } \\
\text { indicates endogeneity }\end{array}$ & $\begin{array}{l}\text { Exogenous: } 10 \% \text { points to be in } \\
\text { labour force; endogenous: } 9 \% \\
\text { points reduction; test indicates } \\
\text { endogeneity }\end{array}$ \\
\hline [102] & $\begin{array}{l}2001, \\
2004-2005\end{array}$ & Australia & $18-64$ & $\begin{array}{l}\text { 50-64: } 11.5 \% \text { points less likely to } \\
\text { be in labour force; } 18-49: 3.9 \% \\
\text { points less likely; all effects } \\
\text { increase when other chronic } \\
\text { diseases are present }\end{array}$ & $\begin{array}{l}\text { No significant effect for diabetes } \\
\text { alone; significant negative effect } \\
\text { if other chronic diseases are } \\
\text { present }\end{array}$ \\
\hline$[100]$ & 1998 & Canada & $15-64$ & $\begin{array}{l}\text { Exogenous: } 19 \% \text { points less likely } \\
\text { to be employed; endogenous: not } \\
\text { significant and positive; test } \\
\text { indicates endogeneity }\end{array}$ & $\begin{array}{l}\text { Exogenous: } 17 \% \text { points less likely } \\
\text { to be employed; endogenous: not } \\
\text { significant and positive and test } \\
\text { indicates exogeneity }\end{array}$ \\
\hline [124] & 1983-1990 & Canada & $18-64$ & \multicolumn{2}{|c|}{$\begin{array}{l}\text { With complications two times less likely to be in labour force; no } \\
\text { significant effect on employment for those in labour force }\end{array}$} \\
\hline [71] & $1992-1993$ & Sweden & $>24$ & \multicolumn{2}{|c|}{$14.2 \%$ points higher retirement rate $(22.9 \text { vs. } 8.7)^{\mathrm{a}}$} \\
\hline [125] & 2004 & $\begin{array}{l}\text { Sweden, Denmark, The } \\
\text { Netherlands, Germany, } \\
\text { Austria, Switzerland, } \\
\text { France, Italy, Spain, } \\
\text { Greece }\end{array}$ & $50-65$ & \multicolumn{2}{|c|}{$\begin{array}{l}\text { For whole dataset: no effect of diabetes on being unemployed, but } \\
\text { increased OR of } 1.33 \text { on being retired. No information on effects by } \\
\text { country }^{\mathrm{a}}\end{array}$} \\
\hline$[101]$ & 2005 & Taiwan & $45-64$ & $\begin{array}{l}\text { Exogenous: } 9 \% \text { points less likely to } \\
\text { be employed; endogenous: } 19 \% \\
\text { points less likely to be employed; } \\
\text { test on whole sample indicates } \\
\text { endogeneity }\end{array}$ & $\begin{array}{l}\text { Exogenous: } 11 \% \text { points less likely } \\
\text { to be employed, endogenous: not } \\
\text { significant and negative }\end{array}$ \\
\hline [98] & & USA & $>44$ & $\begin{array}{l}\text { Exogenous: } 7.4 \% \text { points less likely } \\
\text { to be employed; endogenous: } \\
10.6 \% \text { points less likely but test } \\
\text { indicates exogeneity }\end{array}$ & $\begin{array}{l}\text { Exogenous: } 7.5 \% \text { points less } \\
\text { likely to be employed; } \\
\text { Endogenous: no significant effect } \\
\text { found; test indicates endogeneity }\end{array}$ \\
\hline [99] & 2006 & USA & $\begin{array}{l}>19 \text { at } \\
\text { diagnosis }\end{array}$ & & $\begin{array}{l}\text { Exogenous: } 25.2 \% \text { less likely to } \\
\text { be employed; Endogenous: } \\
45.1 \% \text { less likely to be } \\
\text { employed }\end{array}$ \\
\hline [108] & 1992-2000 & USA & $51-61$ & \multicolumn{2}{|c|}{$\begin{array}{l}\text { More likely to be retired in } 1992 \text { (adjusted OR 1.3). Over } 8 \text { years follow- } \\
\text { up spent } 0.14 \text { incremental years in retirement }^{\mathrm{a}}\end{array}$} \\
\hline [105] & 1996-1997 & USA & $>44$ & $\begin{array}{l}7.5 \% \text { Points less likely to be } \\
\text { employed }\end{array}$ & $\begin{array}{l}\text { No significant effect on } \\
\text { employment chances found }\end{array}$ \\
\hline [110] & 2008 & USA & $35-64$ & $\begin{array}{l}\text { Diabetes negatively related to } \\
\text { employment }(5 \% \text { points } \\
\text { reduction); better diabetes } \\
\text { management }\left(\mathrm{A}_{1 \mathrm{c}}\right) \text { positively } \\
\text { affects employment probabilities; } \\
\mathrm{A}_{1 \mathrm{c}} \text { lowering of } 10 \% \text { increases } \\
\text { employment probability by } \\
0.44 \% \text { points }\end{array}$ & $\begin{array}{l}\text { No significant effect on } \\
\text { employment chances found }\end{array}$ \\
\hline [126] & 1992, 1994 & USA & $51-61$ & $\begin{array}{l}9 \% \text { Points less likely to work } \\
\text { without complications controlled } \\
\text { for, with complications controlled } \\
\text { for } 7.1 \% \text { points less likely }\end{array}$ & $\begin{array}{l}5.9 \% \text { Points less likely to work } \\
\text { without complications controlled } \\
\text { for, with complications } \\
\text { controlled for } 4.4 \% \text { points less } \\
\text { likely but not significant }\end{array}$ \\
\hline [127] & 1997-2005 & USA & $\begin{array}{l}20-44 \text { and } \\
45-64\end{array}$ & \multicolumn{2}{|c|}{$\begin{array}{l}\text { 20-44: proportion with work limitations } 3.1 \% \text { higher; } 45-64 \text { : proportion } \\
\text { not working is } 8.1 \% \text { higher; the proportion work disabled is } 3.4 \% \\
\text { higher; proportion with work limitations is } 5.7 \% \text { higher (all vs. similar } \\
\text { age group without diabetes) }{ }^{\mathrm{a}}\end{array}$} \\
\hline
\end{tabular}


Table 5 continued

\begin{tabular}{|c|c|c|c|c|c|}
\hline \multirow[t]{2}{*}{ References } & \multirow[t]{2}{*}{ Survey year } & \multirow[t]{2}{*}{ Country } & \multirow{2}{*}{$\begin{array}{l}\text { Age } \\
\text { (years) }\end{array}$} & \multicolumn{2}{|l|}{ Effect on employment } \\
\hline & & & & Males & Females \\
\hline$[128]$ & 1990-1995 & USA & & \multicolumn{2}{|c|}{$\begin{array}{l}\text { Unemployment rate for pts with diabetes was } 16 \% \text { compared with } 3 \% \\
\text { among matched comparison group }\end{array}$} \\
\hline [109] & 1989 & USA & $\begin{array}{l}>29 \text { at } \\
\text { diagnosis }\end{array}$ & \multicolumn{2}{|c|}{$\begin{array}{l}3.6 \% \text { less likely to be employed (exogenous), } 12 \% \text { for those with } \\
\text { complications }^{\mathrm{a}}\end{array}$} \\
\hline$[104]$ & 1979-2010 & USA & $>14$ & $\begin{array}{l}\text { Average reduction of employment } \\
\text { probability of } 28 \% \text { points; } \\
\text { strongest employment penalty in } \\
\text { first } 5 \text { years after diagnosis }\end{array}$ & $\begin{array}{l}\text { Average reduction of employment } \\
\text { probability of } 36 \% \text { points; } \\
\text { strongest employment penalty in } \\
\text { first } 15 \text { years after diagnosis }\end{array}$ \\
\hline
\end{tabular}

$A_{l c}$ glycated haemoglobin, $O R$ odds ratio, pts patients

${ }^{a}$ No gender differentiation in study

after diagnosis for men and 11-15 years after diagnosis for women [104].

\subsubsection{Productivity}

For earnings, no effect was found for Mexican-American men in Texas [105], while the highest loss was found for women in the USA ( $\$ 21,392$ per year) [99]. Again looking at diabetes duration, a wage penalty was only found for USA men $6-10$ years after diagnosis, reducing their wage by about $18 \%$ [104]. The only study on a non-HIC, China, tried to tease out the psychological effect of a diabetes diagnosis on subsequent labour income, finding a reduction of $22 \%$ in income for males, but not for females. Further, those with glycated haemoglobin $\left(\mathrm{HbA}_{1 \mathrm{c}}\right)$ between 8 and $10 \%$ experienced the most severe income penalty $(28 \%)$. The study further showed that the adverse effect of a diabetes diagnosis was concentrated among the poorest third of the study population [106]. Another study investigated the effect on earning losses for caregivers of people with diabetes in the UK, finding a reduction of $\$ 2,609$ per year, while the person with diabetes experienced a loss of $\$ 1,744$ per year [107]. For income, a reduction of $\$ 6,250$ per year was found for older USA adults who had been followed between the years 1992 and 2000 [108]. In terms of lost workdays and work hours due to diabetes, the effects ranged from no impact on lost work days on older people [108] and females in the USA [99] to 3.2 lost work days in a USA population within a 2-week period if complications were present [109].

In terms of the methodology used, these studies tended to rarely account for endogeneity, and they mostly used standard regression or matching methods to estimate the impact of diabetes. Three studies [99, 105, 110] corrected for the possibility of a sample selection bias, to account for systematic differences between the working population and the overall population. Only one study additionally applied IV methods and found diabetes to be endogenous, so that its effects on earnings were dramatically understated using naive regression results [99]. For working hours and days missed due to illness, the same study found no indication of endogeneity. Only one study applied an approach other than IV to account for endogeneity, using a difference-indifference model and exploiting a recent diagnosis of diabetes, which was the result of the collection of biomarkers in the survey used, as a natural experiment to measure how income developed between those who were newly diagnosed and those without diabetes in the years following diagnosis [106].

\section{Discussion}

The objectives of this systematic review were to identify new evidence on the economic impact of type 2 diabetes that emerged since 2001 and extend the scope of the review by including studies on the labour market impact of diabetes. We identified studies from a great variety of countries, with large differences in cost estimates across and within countries.

\subsection{General Findings and Developments Since the 2004 Review of Diabetes COI Studies}

An obvious development since the last review is the emergence of COI studies on LMICs. The economic burden related to diabetes found in these studies indicated a strong direct impact on those affected by diabetes. This is reflected in the substantial burden of OOP treatment costs incurred by patients $[10,12,26,67,80,83,85,87,88,91$, 92], with considerable proportions of the annual income being spent on diabetes care. This relative cost burden was generally higher for people with relatively lower household incomes $[83,85,91]$. Health insurance coverage had some protective effects against OOP expenditures, but mainly for those with higher incomes, while the poor often lacked coverage $[83,85,91]$. Once people were covered by health 
Table 6 Studies estimating the relation between diabetes and other productivity outcomes (2001-2014)

\begin{tabular}{|c|c|c|c|c|c|}
\hline \multirow[t]{2}{*}{ References } & \multirow{2}{*}{$\begin{array}{l}\text { Survey } \\
\text { year }\end{array}$} & \multirow[t]{2}{*}{ Country } & \multirow[t]{2}{*}{ Age (years) } & \multicolumn{2}{|l|}{ Effect on other productivity outcomes } \\
\hline & & & & Males & Females \\
\hline [124] & $1983-1990$ & Canada & $18-64$ & \multicolumn{2}{|c|}{$\begin{array}{l}\text { Effect on earnings only when complications are present: reduced to } 72 \% \text { of total } \\
\text { income of controls }{ }^{\mathrm{a}}\end{array}$} \\
\hline [106] & 2009,2011 & China & Not given & \multicolumn{2}{|c|}{$\begin{array}{l}16.3 \% \text { decrease in annual income for newly diagnosed diabetics in } 2011 \text {. Impact } \\
\text { more significant for males and people with Alc levels between } 8.0 \% \text { and } 10.0 \% \text {, } \\
\text { leading to a } 22.0 \% \text { and } 28.0 \% \text { decrease in annual income, respectively. Also } \\
\text { effects are stronger for those in lower income quintiles }\end{array}$} \\
\hline [129] & 1989-2007 & France & $\begin{array}{l}\text { Males } \\
40-50, \\
\text { females } \\
35-50 \text { in } \\
1989\end{array}$ & \multicolumn{2}{|c|}{$\begin{array}{l}\text { 1.7 } \mathrm{HR} \text { to transition from employed to disabled, } 1.6 \mathrm{HR} \text { to be retired, } 7.3 \mathrm{HR} \text { to be } \\
\text { dead; between age } 35 \text { and } 60 \text { each person with diabetes lost } 1.1 \text { years of time in } \\
\text { workforce }^{\mathrm{a}}\end{array}$} \\
\hline [130] & 2010-2013 & $\begin{array}{l}\text { The } \\
\text { Netherlands }\end{array}$ & $45-64$ & \multicolumn{2}{|c|}{$\begin{array}{l}\text { Diabetes reduced work ability measured using WAI by } 2 \% \text {. No significant effect on } \\
\text { productivity was found }\end{array}$} \\
\hline [71] & $1992-1993$ & Sweden & $>24$ & \multicolumn{2}{|l|}{9.4 more sick days $^{\mathrm{a}}$} \\
\hline [107] & 1999 & UK & $<65$ & \multicolumn{2}{|c|}{$\$ 1,744$ lost earnings per year with diabetes; $\$ 2,609$ for carers of people with diabetes ${ }^{a}$} \\
\hline [99] & 2006 & USA & $\begin{array}{l}>19 \text { at } \\
\text { diagnosis }\end{array}$ & & $\begin{array}{l}\text { Exogenous: } \$ 3,118 \text { loss in earnings } \\
\text { per year, Endogenous: } \$ 21,392 ; \\
\text { Exogenous: } 2 \text { working hours less } \\
\text { per week, no significant effect on } \\
\text { missed workdays per year, } \\
\text { endogenous: no significant effect } \\
\text { on working hours or workdays } \\
\text { missed }\end{array}$ \\
\hline$[108]$ & $1992-2000$ & USA & $51-61$ & \multicolumn{2}{|c|}{$\begin{array}{l}\text { Lost income of } \$ 50,004 \text { from } 1992 \text { to } 2000 \text { per capita or } \$ 6,250 \text { per year, for whole } \\
\text { US population of same age } \$ 85.6 \text { billion or } \$ 10.7 \text { billion per year; people with } \\
\text { diabetes more likely to have taken sick days in } 1992 \text { (adjusted OR } 1.3)^{\mathrm{a}}\end{array}$} \\
\hline [131] & 2002 & USA & $\begin{array}{l}\text { Working } \\
\text { age }\end{array}$ & \multicolumn{2}{|l|}{ No significant effect on work days ${ }^{a}$} \\
\hline$[105]$ & 1996-1997 & USA & $>44$ & No significant effect on earnings & $\begin{array}{l}\text { Women with diabetes earn } 84 \% \\
\text { less }\end{array}$ \\
\hline$[110]$ & 2008 & USA & $35-64$ & $\begin{array}{l}\text { Wages reduced by } 0.74 \% \text { due to diabetes; for } \\
\text { every } 10 \% \text { reduction in } \mathrm{A}_{1 \mathrm{c}} \text { wages rise by } \\
0.62 \% . \mathrm{A}_{1 \mathrm{c}}>8 \text { was related to decreasing } \\
\text { wages }\end{array}$ & $\begin{array}{l}\text { No significant effect of diabetes on } \\
\text { female earnings; no effect of } \\
\text { blood sugar management for } \\
\text { women, } A_{1 \mathrm{c}} \text { levels just below } 6 \text { to } \\
\text { just above } 7 \text { were related to lower } \\
\text { wages }\end{array}$ \\
\hline [132] & 2005-2009 & USA & $>16$ & \multicolumn{2}{|l|}{ Lost earnings per year of $\$ 2,221^{a}$} \\
\hline [126] & 1992,1994 & USA & $51-61$ & No significant effect on number of work days & 2.5 more lost workdays per year \\
\hline [128] & 1990-1995 & USA & & \multicolumn{2}{|c|}{$\begin{array}{l}71 \% \text { of those with diabetes had an annual income of less than } \$ 20,000 \text { compared with } \\
59 \% \text { of the matched respondents }{ }^{\mathrm{a}}\end{array}$} \\
\hline [109] & 1989 & USA & $\begin{array}{l}>29 \text { at } \\
\text { diagnosis }\end{array}$ & \multicolumn{2}{|l|}{$\begin{array}{l}\text { No significant effect on work days for } \mathrm{T} 2 \mathrm{D} \text {, for } \\
\text { those with complications } 3.2 \text { days lost within } \\
2 \text { weeks }\end{array}$} \\
\hline [133] & NA & USA & $>45$ & \multicolumn{2}{|c|}{$\begin{array}{l}\text { For every dollar of labour income lost by adults with diabetes, a further income } \\
\text { reduction of } \$ 0.48 \text { occurs in the community. Total output reduction for upper bound } \\
\text { estimate is } \$ 300 \text { million for the local economy }\end{array}$} \\
\hline [104] & 1979-2010 & USA & $>14$ & $\begin{array}{l}\text { No general effect of T2D on wages; some } \\
\text { evidence of wage penalty of about } 18 \% \\
6-10 \text { years after diagnosis }\end{array}$ & $\begin{array}{l}\text { No strong evidence found for wage } \\
\text { penalty for females }\end{array}$ \\
\hline
\end{tabular}

$A_{l c}$ glycated haemoglobin, $H R$ hazard ratio, $O R$ odds ratio, T2D type 2 diabetes, WAI Work Ability Index

${ }^{\text {a }}$ No gender differentiation in study 
insurance, their risk of incurring catastrophic expenditures decreased significantly [10]. An important cost factor that was predominantly investigated in studies on LMICs were non-medical costs for transportation, informal healthcare or food, which were found to considerably add to the experienced diabetes cost burden [67, 80, 81, 88, 92].

In terms of the costing methodology applied in COI studies, the number of studies estimating the excess costs of diabetes increased since the Ettaro et al. [3] review. Those studies either used regression analysis or matching to adjust for the differences between people with diabetes and those without, accounting at least for age and gender, but often also for other socioeconomic, geographic and demographic differences. Other widely used approaches to estimate direct healthcare costs from the perspective of the healthcare system or private insurance included the disease-attributable and-slightly less frequently-the attributable-fraction approach. For cost assessment in LMICs, studies often either estimated total healthcare costs or carried out self-administered surveys. While Ettaro et al. [3] suggested an increased use of disease-attributable approaches to arrive at more exact estimates of the costs of diabetes, the evidence found in this review indicates that using an incremental cost approach via matching or regression analysis could provide more accurate results, due to its ability to capture costs otherwise not directly traceable to diabetes. Nonetheless, the use of the estimation technique always hinges on the availability of appropriate data, with regression or matching analyses requiring information on people without diabetes to be used as a control group. Therefore, the estimation approach needs to be tailored to the available data.

Compared with the evidence reviewed by Ettaro et al. [3], the field has generally advanced with respect to the analysis of costs in different ethnic and age groups. Two studies investigated differences between racial groups in the USA, showing that while ethnic minorities spend less on diabetes healthcare than Whites, this difference seems to be mainly based on differences in access to care between Whites and Blacks or Hispanics [39, 50]. In terms of age, studies found an increase in healthcare costs with age as well as with, in some cases, the duration of diabetes. A recurring problem was that many studies did not distinguish between diabetes types, making it difficult to exactly attribute the costs to the respective diabetes types.

To explore the reasons for the wide heterogeneity in direct cost estimates across studies, we performed a regression analysis, which indicated that an important determinant for the cost variation across countries could be the economic wealth of the country (proxied by GDP per capita), similar to what was found in a review of indirect costs of various chronic diseases [111], possibly due to differences in the availability and affordability of diabetes care between HICs and LMICs [112, 113].
Further, studies on the USA seem to estimate consistently higher costs than studies on other countries, even when accounting for differences in GDP per capita. The higher direct costs of diabetes estimated for the USA are in line with the generally higher healthcare expenditures in the USA compared with countries with similar income levels, and could be the result of exceptionally high service fees [8] and prices paid in the USA healthcare system [114, $115]$.

Because of the small sample size on which our analysis was based, these results must be interpreted with caution, and other factors could still be important. For instance, other evidence suggests that different costing approaches have a considerable effect on diabetes cost estimates [51, 60]. Furthermore, the perspective taken, different data sources and populations investigated and decisions on the cost components included are likely important in explaining within-country heterogeneity. In particular, the inclusion of diabetes complications and decisions about which complication(s) to include, as well as the extent to which costs for these diseases are attributable to diabetes, can significantly affect the results. Not all studies in the review provide extensive information about how they include complications and some do not include them at all.

Finally, the quality of the data used could have affected the cost estimates. Many studies in LMICs relied on selfreported data from small household surveys, limiting their generalizability and leading their results to be prone to recall bias. Further, these studies often identified people with diabetes via their use of healthcare institutions, which excluded a potentially important section of the population in LMICs unable to access formal care, possibly leading to an overestimation of the average diabetes-related costs.

\subsection{Labour market studies}

Turning to the effects of diabetes on the labour market, the existing studies showed, almost consistently, with the exception of Canada [100] and one study on the USA [102], that the employment probabilities of men were affected more adversely by the disease than those of women. However, while most studies have tried to tentatively explain these gender differences, the reasons for this have not been investigated in depth. The studies also showed that, when interpreting this research, it is important to consider whether a study has tried to account for unobservable factors or reverse causality, as otherwise the results might be misleading. Nonetheless, all studies using IV techniques used similar instruments to achieve identification, providing scope for further research using different identification strategies to further explore how endogeneity might affect the results. What has been apparent is the lack of research on labour market outcomes of diabetes in LMICs, with 
only one study investigating the effect of diabetes on labour income in China [106]. This deficit might be due to a limited availability of suitable data sources containing sufficient information to allow for a similar investigation of the topic.

The potential for rich, good-quality data sources to aid the investigation of the economic impact of diabetes can be illustrated by the several studies that used data from the Lower Rio Grande Valley in Texas. These studies demonstrate the evolution of methodology and data from the use of single equation regression models [105] to the use of IV methods [98] and-finally-biometric data on blood glucose values [110]. While the first two methods allowed the investigation of the general effect of diabetes on employment chances, the latter was able to assess the impact according to how diabetes was managed by the patient, as proxied by the measured biomarkers. The study found that the main adverse effect was due to having diabetes regardless of how it was managed and that improvements in management only had minor positive effects. The authors concluded that investments in the prevention of diabetes would likely be more effective than improved diabetes management.

The latter study and the study by Liu and Zhou [106] also show how biometric data (e.g. blood glucose values) can be used to arrive at a deeper understanding of the economic effects of diabetes. This information makes it possible to investigate the impact of diabetes according to the severity of the disease and also allows for the consideration of previously undiagnosed people with diabetes, increasing the policy relevance of the research.

\subsection{Comparison of COI and Labour Market Studies: Common Themes and Lessons Learnt}

The results of both fields, COI and labour market studies, show a considerable adverse impact of diabetes in terms of costs to society, health systems, individuals and employers and in terms of a reduction in the productive workforce and productivity in general. Both research strands particularly indicate that the adverse effects of diabetes increase with diabetes duration as well as with the severity of the disease, judged by the high complication costs estimated in COI studies and the larger employment and income penalties for those with a longer disease duration or higher blood glucose levels.

Nonetheless, several lessons can be learned for each field from advancements in the other field. Future COI studies would, for instance, benefit from the more frequent use of biomarker data. This would allow for a more precise analysis of the costs of diabetes according to the severity of the disease and help inform researchers and policy makers about the possible economic effects of achieving certain treatment goals, e.g., a reduction in blood glucose values.

Also, and in contrast to the labour market outcomes literature, the endogeneity problem has hitherto not been addressed in any form in studies estimating direct healthcare or productivity costs, despite it being an equally important challenge in this domain. A possible bias could arise if some people developed diabetes as a result of an unobserved accident or illness, likely resulting in an overestimation of the costs. Endogeneity could also be introduced if people with diabetes became poorer as a result of the disease and consequently were not able to spend as much on their treatment as they would like to, leading to an underestimation of the true monetary cost of diabetes. Furthermore, an endogeneity bias would be introduced if diabetes was correlated with poverty so that diabetes prevalence would be disproportionately high in subgroups with less resources and consequently less access to care. This would lead to an underestimation of the healthcare costs of diabetes. Endogeneity in COI studies has recently been addressed for the estimation of healthcare costs of obesity, suggesting that direct costs would have been underestimated, had the study not accounted for endogeneity [116]. It appears that, on the basis of the studies identified in our review, a similar and worthwhile approach could and should be applied to the case of type 2 diabetes.

Yet the labour market studies also stand to gain from adopting certain approaches that are more common in COI studies. To date, only few labour market studies have used the incidence approach found for COI studies to follow people with diabetes over a certain time period from their diagnosis onwards, in order to further explore how the effect of diabetes on employment and productivity measures develops over time. So far, only one study has done this using a rigorous econometric panel data analysis [104], but more similar studies using other populations would be helpful to establish patterns reflecting the impact of diabetes on the labour market along the continuity of disease duration.

Some further recommendations may be derived for future COI and labour market studies on diabetes:

1. For COI studies, the estimation of incremental costswherever possible-appears to be most suitable for diabetes, as it more accurately accounts for costs of comorbidities and for less obviously related disease costs $[51,60]$. More information that can guide researchers in their choice of methods already exists and should be referred to when performing a COI study [95].

2. If possible, the use of convenience samples of people with diabetes visiting a healthcare institution should be avoided, particularly in LMICs, as it excludes those not able or willing to visit a clinic for treatment due to 
economic reasons, leaving out a potentially important proportion of diabetes patients.

3. The interpretation of the COI results always hinges on the amount of information provided about, among others, the aim of the study, the perspective adopted and the cost components included as well as the estimation approach used. A discussion of how these choices might affect the estimates should also be part of every COI study. Researchers should therefore consult available guidance from the literature that sets out what information should ideally be included in a COI study [96] to increase the transparency and usability of their research.

4. For labour market studies, more evidence from LMICs is needed. There is scope for exploring existing household datasets from LMICs that contain information on diabetes [117]. In some cases, panel data are (or may come) available, which would allow the investigation of the effects of diabetes over time as well as improve the degree of causal inference by controlling for unobserved heterogeneity.

5. As for labour market studies, other ways of achieving identification should be explored to reduce the reliance on IV methods using the family history of diabetes as the sole instrument. The increasing richness of information provided in recent data sets could be used to this effect, also taking into account other quasiexperimental econometric methods [118].

\subsection{Limitations}

A possible limitation of this review is the decision to refrain from excluding studies based on certain quality criteria, such as study design, costing methodology, sample size or reporting standards. This might have resulted in the inclusion of lower-quality studies with less reliable estimates, compromising the comparability across countries, particularly between LMICs and HICs, as study designs differed considerably. On the other hand, our overarching objective was to ensure a truly globally comprehensive overview of the literature on the economic impact of diabetes, including evidence from LMICs, which, for reasons often beyond the control of the researchers, may have been of limited quality and thus would have been excluded had we applied stringent quality benchmarks. Further, any attempt to apply a quality threshold would have faced the challenge of dealing with the absence of a formal checklist to follow in critically appraising the quality of COI studies. Rather than interpreting it as a limitation, we see the identification and synthesis of LMIC studies as a unique added value of this review, when compared to the Ettaro et al. [3] review published in 2004.
Notably, we also abstained from any language restrictions, which would have particularly excluded evidence from Spanish speaking and Eastern European countries. Taken together, these factors have resulted in a large number of included studies, allowing for an (albeit exploratory) statistical investigation of the heterogeneity in diabetes cost estimates as a complement to the narrative analysis. We therefore feel that the advantages of refraining from too stringent inclusion criteria more than outweigh the possible negative consequences of including potentially lower-quality studies.

Further, our search was limited to studies after the year 2000. While for COI studies a previous review covered the literature until 2000, this is not the case for the literature on labour market effects of diabetes and we therefore cannot exclude the possibility of having missed some relevant (if old) studies. ${ }^{3}$

\section{Conclusion}

This review has provided an updated and considerably expanded picture of the literature on the global economic impact of type 2 diabetes. The results show a considerable impact of diabetes in terms of costs to society, health systems, individuals and employers and in terms of a reduction in the productive workforce and productivity in general. Studies on the costs of diabetes now provide evidence from HICs as well as LMICs, using a variety of study designs to estimate the costs of diabetes. The evidence indicates a particularly strong and direct economic impact of type 2 diabetes on people's livelihoods in lowerincome settings. Studies on labour market outcomes so far have been confined, almost exclusively, to HICs, leaving space for further studies in LMICs to provide additional evidence of the effect of diabetes in these countries. An issue not yet covered in diabetes COI studies - in striking contrast to labour market outcome studies-has been the possible bias introduced by endogeneity, providing an opportunity for advancing research in this area.

Acknowledgments The work of MS on this paper was partially funded by the Centre for Diet and Activity Research (CEDAR), a UKCRC Public Health Research Centre of Excellence. Funding from the British Heart Foundation, Cancer Research UK, Economic and Social Research Council (ESRC), Medical Research Council (MRC),

\footnotetext{
${ }^{3}$ We have checked the references of our included labour market studies for any relevant studies published before 2001. We could find only one relevant study from 1998 investigating how employment chances and family income were affected by diabetes in the USA, comparing samples from 1976, 1988 and 1992 and finding significant adverse effects of diabetes on employment chances but not on family income [134]. The effect for women decreased somewhat between 1976 and 1992, while the effect increased for men. The study did not account for the possible endogeneity of diabetes nor selection bias when estimating the effects on income.
} 
the National Institute for Health Research, and the Wellcome Trust, under the auspices of the UK Clinical Research Collaboration, is gratefully acknowledged.

Author contributions TS, OA and MS planned the work and finalized the manuscripts. TS carried out the database search, extracted, analysed and interpreted the data and produced the draft of the manuscript. OA also performed data extraction and contributed to the production of the first draft. MS oversaw the development of the work, contributed to the various drafts of the manuscript and provided guidance. TS is the guarantor for the overall content.

Open Access This article is distributed under the terms of the Creative Commons Attribution Noncommercial License which permits any noncommercial use, distribution, and reproduction in any medium, provided the original author(s) and the source are credited.

\section{Appendix: A1. What is Endogeneity?}

Endogeneity is a statistical problem that occurs in regression models if the assumptions about the flow or direction of causality are incorrect. If endogeneity is ignored, it could be that claims about causality between two variables or the magnitude of the effect are false. In general, one can only be certain about a causal relationship of the effect of $x$ on $y$ if the following three conditions are met [119]:

- $y$ follows $x$ temporally

- $y$ changes as $x$ changes (and this relationship is statistically significant)

- no other causes should eliminate the relation between $x$ and $y$.

Three major causes of endogeneity violate the conditions above.

\section{Omitted Variables}

When a regression is run to determine the causal effect of variable $x$ on variable $y$, but there are unobserved variables that affect variables $x$ or $x$ and $y$ simultaneously, the estimated effect of $x$ on $y$ will be biased. For the case of type 2 diabetes and employment chances, there is the danger that, for example, personal traits like ambition, which are hard to observe, could influence the probability of developing type 2 diabetes through their effect on a person's lifestyle, but they could also simultaneously affect the chances of employment through their influence on a person's determination to find work or to perform well at work. If we are not able to control for this, then our estimate of the effect of diabetes on employment chances might, at least partially, represent the effect of personal traits on employment chances. As a result, our estimate of the effect of diabetes is biased and does not represent the true size of the relationship between the two variables.
Simultaneity

Simultaneity is present if our outcome variable $y$ and our variable of interest $x$ influence each other simultaneously, so that $y$ not only is affected by $x$ but $x$ is also affected by $y$. In the case of type 2 diabetes and labour market outcomes, not only could diabetes influence employment chances or work-related income, but also resulting changes in lifestyle due to employment or an increase in income could affect the probabilities of developing diabetes. Due to an increase in income, people could change their diet or change towards a less active lifestyle, which in turn would make them more likely to develop type 2 diabetes.

\section{Measurement Error}

Measurement errors occur when the independent variable $x$ is imprecisely measured. Here, this would be the case if people in a survey did not remember whether they have been diagnosed with type 2 diabetes and gave an incorrect answer.

Several solutions to the problem of endogeneity exist, but only the use of IV techniques has the potential to deal with all three causes of endogeneity at once. Endogeneity is a problem, because the variable of interest, here diabetes, is correlated with the error term of the estimated model, which includes all omitted variables as well as the effect of $y$ on $x$ and, if measurement error is present, the true values. To do this, one needs to find a suitable instrument that needs to fulfil the following conditions:

- it must be causally related to the endogenous variable $x$, and

- it should not be correlated to the dependent variable $y$ other than through its correlation with $x$.

This instrument is then used in a first regression to obtain predicted values of the problematic endogenous regressor. Because the instrument is not correlated with the error term, these predicted values of the endogenous variable will also be uncorrelated and can then be used in a second regression to predict the dependent variable $y$. The estimated coefficients of this second stage can then be regarded as consistent estimates.

In the case of type 2 diabetes and labour market outcomes, an instrument has to predict the development of diabetes without being otherwise causally related to any of the labour market outcomes, be it employment chances, wages or some other measure of productivity. The instrument of choice so far has been the family history of diabetes. It has been shown that a considerable part of the risk of developing type 2 diabetes is hereditary [120-122]. This fact is exploited when the instrument is used and it is 
assumed that this is the only pathway through which a family history of diabetes affects a person's diabetes risk, and also that, for example, parental diabetes does not affect the person's labour market outcomes directly.

The most common estimation techniques for the estimation of IV regressions are the linear IV model and the bivariate probit model. The latter is often deemed more apt for models where both the outcome and the IV are binary, so either 0 or 1 , which is the case for employment as an outcome variable as well as diabetes family history as an instrument. Nonetheless, there is some discussion in the econometrics literature regarding the best method to estimate these cases, as it has also been argued that, because the linear IV technique does not depend on the assumption of normality of the error terms, in contrast to the bivariate probit model, its results are more reliable in the case of non-normality, but can sometimes lead to imprecise estimators, which can no longer be interpreted meaningfully [123]. Both methods can be found in the reviewed papers.

\section{A2. Country Codes}

See Table 7.

Table 7 Countries and their respective country codes as used in the review

\begin{tabular}{|c|c|c|c|}
\hline Country & $\begin{array}{l}\text { Country } \\
\text { code }\end{array}$ & Country & $\begin{array}{l}\text { Country } \\
\text { code }\end{array}$ \\
\hline $\begin{array}{l}35 \text { Developing } \\
\text { countries }\end{array}$ & LMIC & Jamaica & JAM \\
\hline Argentina & ARG & Japan & JPN \\
\hline Australia & AUS & $\begin{array}{l}\text { Latin America and } \\
\text { Caribbean }\end{array}$ & LAC \\
\hline Bahamas & BHS & Mexico & MEX \\
\hline Barbados & BRB & The Netherlands & NLD \\
\hline Belgium & BEL & Nicaragua & NIC \\
\hline Bolivia & BOL & Nigeria & NGA \\
\hline Brazil & BRA & Norway & NOR \\
\hline Canada & CAN & Pakistan & PAK \\
\hline Chile & CHL & Panama & PAN \\
\hline China & $\mathrm{CHN}$ & Paraguay & PRY \\
\hline Colombia & $\mathrm{COL}$ & Peru & PER \\
\hline Costa Rica & CRI & Serbia & SRB \\
\hline Cuba & CUB & Spain & ESP \\
\hline $\begin{array}{l}\text { Czech } \\
\text { Republic }\end{array}$ & CZE & Sudan & SDN \\
\hline Denmark & DNK & Sweden & SWE \\
\hline $\begin{array}{r}\text { Dominican } \\
\text { Republic }\end{array}$ & DOM & Switzerland & $\mathrm{CHE}$ \\
\hline Ecuador & ECU & Taiwan & TWN \\
\hline El Salvador & SLV & Thailand & THA \\
\hline
\end{tabular}

Table 7 continued

\begin{tabular}{llll}
\hline Country & $\begin{array}{l}\text { Country } \\
\text { code }\end{array}$ & Country & $\begin{array}{l}\text { Country } \\
\text { code }\end{array}$ \\
\hline $\begin{array}{l}\text { 8 Western } \\
\text { European } \\
\text { Countries }\end{array}$ & EUR & $\begin{array}{l}\text { The Bahamas, Barbados, } \\
\text { Jamaica, Trinidad and } \\
\text { Tobago }\end{array}$ & CARICOM \\
France & FRA & Trinidad and Tobago & TTO \\
Germany & DEU & UnE \\
Guatemala & GTM & United Arab Emirates & ARE \\
Guyana & GUY & United Kingdom & GBR \\
Haiti & HTI & USA & USA \\
Honduras & HND & Uruguay & URY \\
Hong Kong & HKG & Venezuela & VEN \\
India & IND & WHO African Region & AFR \\
Iran, Islamic & IRN & & \\
$\quad$ Rep. & IRL & & \\
Ireland & ISR & & \\
Israel & ITA & & \\
Italy & & & \\
\hline
\end{tabular}

\section{References}

1. International Diabetes Federation. Diabetes Atlas. 6th ed. International Diabetes Federation; 2013.

2. Hu FB. Globalization of diabetes: the role of diet, lifestyle, and genes. Diabetes Care. 2011;34:1249-57.

3. Ettaro L, Songer TJ, Zhang P, Engelgau MM. Cost-of-illness studies in diabetes mellitus. Pharmacoeconomics. 2004;22: 149-64.

4. Segel JE. Cost-of-Illness Studies-A Primer. RTI-UNC Center of Excellence in Health Promotion Economics; 2006.

5. Moher D, Liberati A, Tetzlaff J, Altman DG. Preferred reporting items for systematic reviews and meta-analyses: the PRISMA statement. PLoS Med. 2009;6:e1000097.

6. Shemilt I, Thomas J, Morciano M. A web-based tool for adjusting costs to a specific target currency and price year. Evid Policy J Res Debate Pract. 2010;6:51-9.

7. World Bank. World Bank Analytical Classifications [Internet]. [cited 2014 Feb 24]. Available from: http://siteresources. worldbank.org/DATASTATISTICS/Resources/OGHIST.xls.

8. Laugesen MJ, Glied SA. Higher fees paid to US physicians drive higher spending for physician services compared to other countries. Health affairs (Project Hope). 2011;30:1647-56.

9. Kirigia JM, Sambo HB, Sambo LG, Barry SP. Economic burden of diabetes mellitus in the WHO African region. BMC Int Health Hum Rights. 2009;9:6.

10. Smith-Spangler CM, Bhattacharya J, Goldhaber-Fiebert JD. Diabetes, its treatment, and catastrophic medical spending in 35 developing countries. Diabetes Care. 2012;35:319-26.

11. Boutayeb A, Boutayeb W. Estimation of the direct cost of diabetes in the Arab region. Mediterr J Nutr Metab. 2014;7:21-32.

12. Suleiman I, Fadeke O, Okubanjo O. Pharmacoeconomic evaluation of anti-diabetic therapy in a Nigerian Tertiary Health Institution. Ann African Med. 2006;5:132-7.

13. Yang W, Zhao W, Xiao J, Li R, Zhang P, Kissimova-Skarbek K, et al. Medical care and payment for diabetes in China: enormous threat and great opportunity. PloS One. 2012;7:e39513. 
14. Barceló A, Aedo C, Rajpathak S, Robles S. The cost of diabetes in Latin America and the Caribbean. Bull World Health Organ. 2003;81:19-27.

15. Jönsson B. Revealing the cost of Type II diabetes in Europe. Diabetologia. 2002;45:S5-12.

16. Ohinmaa A, Jacobs P, Simpson S, Johnson JA. The projection of prevalence and cost of diabetes in Canada: 2000 to 2016. Can J Diabetes. 2004;28:116-23.

17. Lau RS, Ohinmaa A, Johnson JA. Predicting the future burden of diabetes in Alberta from 2008 to 2035. Can J Diabetes. 2011;35:274-81.

18. Pohar SL, Majumdar SR, Johnson JA. Health care costs and mortality for Canadian urban and rural patients with diabetes: population-based trends from 1993-2001. Clin Thera. 2007;29:1316-24.

19. González JC, Walker JH, Einarson TR, González JC. Cost-ofillness study of type 2 diabetes mellitus in Colombia. Revista panamericana de salud pública. Pan Am J Public Health. 2009;26:55-63.

20. Horak P. Pharmacoeconomy of diabetes mellitus - trends in the Czech Republic. Vnitr Lek. 2009;55:331-40.

21. Martin S, Schramm W, Schneider B, Neeser K, Weber C, Lodwig V, et al. Epidemiology of complications and total treatment costs from diagnosis of Type 2 diabetes in Germany (ROSSO 4). Exp Clin Endocrinol Diabetes. 2007;115:495-501.

22. Nolan JJ, O'Halloran D, McKenna TJ, Firth R, Redmond S. The cost of treating type 2 diabetes (CODEIRE). Irish Med J. 2006;99:307-10.

23. Lucioni C, Garancini MP, Massi-Benedetti M, Mazzi S, Serra G. The costs of type 2 diabetes mellitus in Italy: A CODE-2 substudy. Treat Endocrinol. 2003;2:121-33.

24. Morsanutto A, Berto P, Lopatriello S, Gelisio R, Voinovich D, Cippo PP, et al. Major complications have an impact on total annual medical cost of diabetes: results of a database analysis. J Diabetes Complicat. 2006;20:163-9.

25. Nakamura K, Okamura T, Kanda H, Hayakawa T, Murakami Y, Okayama A, et al. Medical expenditure for diabetic patients: a 10-year follow-up study of National Health Insurance in Shiga, Japan. Public Health. 2008;122:1226-8.

26. Arredondo A, Barcelo A. The economic burden of out-of-pocket medical expenditures for patients seeking diabetes care in Mexico. Diabetologia. 2007;50:2408-9.

27. Arredondo A, Zúñiga A. Economic consequences of epidemiological changes in diabetes in middle-income countries: The Mexican case. Diabetes Care. 2004;27:104-9.

28. Arredondo A, Zúñiga A, Parada I. Health care costs and financial consequences of epidemiological changes in chronic diseases in Latin America: evidence from Mexico. Public Health. 2005;119:711-20.

29. Arredondo A, De Icaza E. Costs of diabetes in Latin America: evidences from the Mexican case. Value Health. 2011;14: S85-8.

30. Redekop WK, Koopmanschap MA, Rutten GEHM, Wolffenbuttel BHR, Stolk RP, Niessen LW. Resource consumption and costs in Dutch patients with type 2 diabetes mellitus. Results from 29 general practices. Diabet Med J Br Diabet Assoc. 2002;19:246-53.

31. Bjegovic V, Terzic Z, Marinkovic J, Lalic N, Sipetic S, Laaser $\mathrm{U}$. The burden of type 2 diabetes in Serbia and the cost-effectiveness of its management. Eur J Health Econ HEPAC Health Econ Prev Care. 2007;8:97-103.

32. Oliva J, Lobo F, Molina B, Monereo S. Direct health care costs of diabetic patients in Spain. Diabetes Care. 2004;27:2616-21.

33. Ringborg A, Martinell M, Stålhammar J, Yin DD, Lindgren P. Resource use and costs of type 2 diabetes in Sweden-estimates from population-based register data. Int J Clin Pract. 2008;62: 708-16.

34. Chi M, Lee $\mathrm{C}, \mathrm{Wu}$ S. The prevalence of chronic conditions and medical expenditures of the elderly by chronic condition indicator (CCI). Arch Gerontol Geriatr. 2011;52:284-9.

35. Zhou H, Isaman DJM, Messinger S, Brown MB, Klein R, Brandle $\mathrm{M}$, et al. A computer simulation model of diabetes progression, quality of life, and cost. Diabetes Care. 2005;28:2856-63.

36. Condliffe S, Link CR, Parasuraman S, Pollack MF. The effects of hypertension and obesity on total health-care expenditures of diabetes patients in the United States. Appl Econ Lett. 2013;20:649-52.

37. Brandle M, Zhou H, Smith BRK, Marriott D, Burke R, Tabaei $\mathrm{BP}$, et al. The direct medical cost of type 2 diabetes. Diabetes Care. 2003;26:2300-4.

38. Peele PB, Lave JR, Songer TJ. Diabetes in employer-sponsored health insurance. Diabetes Care. 2002;25:1964-8.

39. Lee J-A, Liu C-F, Sales AE. Racial and ethnic differences in diabetes care and health care use and costs. Prev Chronic Dis. 2006;3:A85

40. Maciejewski M, Maynard C. Diabetes-related utilization and costs for inpatient and outpatient services in the Veterans Administration. Diabetes Care. 2004;27:B69-73.

41. Abdulkadri AO, Cunningham-Myrie C, Forrester T. Economic burden of diabetes and hypertension in CARICOM States. Soc Econ Stud. 2009;58:175-97.

42. Davis WA, Knuiman MW, Hendrie D, Davis TME. The obesitydriven rising costs of type 2 diabetes in Australia: projections from the Fremantle Diabetes Study. Intern Med J. 2006;36: 155-61.

43. Simpson SH, Corabian P, Jacobs P, Johnson JA. The cost of major comorbidity in people with diabetes mellitus. Can Med Assoc J. 2003;168:1661-7.

44. Rodríguez Bolaños R de LÁ, Reynales Shigematsu LM, Jiménez Ruíz JA, Juárez Márquezy SA, Hernández Ávila M, R. D los ARB. Direct costs of medical care for patients with type 2 diabetes mellitus in Mexico: micro-costing analysis. Revista Panamericana de Salud Publica/Pan Am J Public Health. 2010;28:412-20.

45. Solli O, Jenssen T, Kristiansen IS. Diabetes: cost of illness in Norway. BMC Endocr Disord. 2010;10:15.

46. Ballesta M, Carral F, Olveira G, Girón JA, Aguilar M. Economic cost associated with type II diabetes in Spanish patients. Eur J Health Econ HEPAC Health Econ Prev Care. 2006;7: $270-5$.

47. Mata M, Antoñanzas F, Tafalla M, Sanz P. [The cost of type 2 diabetes in Spain: the CODE-2 study]. Gaceta sanitaria/ S.E.S.P.A.S. 2002;16:511-20.

48. Lin T, Chou P, Tsai S-T, Lee Y-C, Tai T-Y. Predicting factors associated with costs of diabetic patients in Taiwan. Diabetes Res Clin Pract. 2004;63:119-25.

49. Dall T, Nikolov P, Hogan P. Economic costs of diabetes in the US in 2002. Diabetes Care. 2003;26:917-32.

50. Buescher PA, Whitmire JT, Pullen-Smith B. Medical care costs for diabetes associated with health disparities among adult Medicaid enrollees in North Carolina. North Carolina Med J. 2010;71:319-24.

51. Tunceli O, Wade R, Gu T, Bouchard JR, Aagren M, Luo W. Cost of diabetes: comparison of disease-attributable and matched cohort cost estimation methods. Curr Med Res Opin. 2010;26:1827-34.

52. Johnson JA, Pohar SL, Majumdar SR. Health care use and costs in the decade after identification of type 1 and type 2 diabetes: a population-based study. Diabetes Care. 2006;29:2403-8. 
53. Honkasalo MT, Linna M, Sane T, Honkasalo A, Elonheimo O. A comparative study of two various models of organising diabetes follow-up in public primary health care-the model influences the use of services, their quality and costs. BMC Health Serv Res. 2014;14:26.

54. Bastida JL, Aguilar PS, Gonzalez BD. The social and economic cost of diabetes mellitus. Atencion primaria / Sociedad Española de Medicina de Familia y Comunitaria. 2002;29:145-50.

55. Dall T, Mann SE, Zhang Y, Martin J, Chen Y, Hogan P, et al. Economic costs of diabetes in the U.S. in 2007. Diabetes Care. 2008;31:596-615.

56. Dawson KG, Gomes D, Gerstein H, Blanchard JF, Kahler KH. The economic cost of diabetes in Canada, 1998. Diabetes Care. 2002;25:1303-7.

57. Schmitt-Koopmann I, Schwenkglenks M, Spinas GA, Szucs TD. Direct medical costs of type 2 diabetes and its complications in Switzerland. Eur J Public Health. 2004;14:3-9.

58. Dall TM, Zhang Y, Chen YJ, Quick WW, Yang WG, Fogli J. The economic burden of diabetes. Health Affairs. 2010;29:297-303.

59. Bolin K, Gip C, Mörk A-C, Lindgren B. Diabetes, healthcare cost and loss of productivity in Sweden 1987 and 2005-a register-based approach. Diabet Med. 2009;26:928-34.

60. Honeycutt AA, Segel JE, Hoerger TJ, Finkelstein EA. Comparing cost-of-illness estimates from alternative approaches: an application to diabetes. Health Serv Res. 2009;44:303-20.

61. Lesniowska J, Schubert A, Wojna M, Skrzekowska-Baran I, Fedyna M. Costs of Diabetes and Its Complications in Poland. European Journal of Health Economics. 2014;15:653-60.

62. Pohar SL, Johnson JA. Health care utilization and costs in Saskatchewan's registered Indian population with diabetes. BMC Health Serv Res. 2007;7:126.

63. Ricordeau P, Weill A, Vallier N, Bourrel R, Schwartz D, Guilhot $\mathrm{J}$, et al. The prevalence and cost of diabetes in metropolitan France: what trends between 1998 and 2000? Diabetes Metab. 2003;29:497-504.

64. Köster I, Huppertz E, Hauner H, Schubert I. Direct costs of diabetes mellitus in Germany-CoDiM 2000-2007. Exp Clin Endocrinol Diabetes. 2011;119:377-85.

65. Köster I, von Ferber L, Ihle P, Schubert I, Hauner H. The cost burden of diabetes mellitus: the evidence from Germany-the CoDiM study. Diabetologia. 2006;49:1498-504.

66. Köster I, Schubert I, Huppertz E. Follow up of the CoDiMStudy: cost of diabetes mellitus 2000-2009. Dtsch Med Wochenschr. 2012;137:1013-6.

67. Esteghamati A, Khalilzadeh O, Anvari M, Meysamie A, Abbasi M, Forouzanfar M, et al. The economic costs of diabetes: a population-based study in Tehran, Iran. Diabetologia. 2009;52: 1520-7.

68. Chodick G, Heymann AD, Wood F, Kokia E. The direct medical cost of diabetes in Israel. Eur J Health Econ HEPAC Health Econ Prev Care. 2005;6:166-71.

69. Marchesini G, Forlani G, Rossi E, Berti A, De Rosa M. The direct economic cost of pharmacologically-treated diabetes in Italy-2006. The ARNO observatory. Nutr Metab Cardiovasc Dis NMCD. 2011;21:339-46.

70. Bruno G, Picariello R, Petrelli A, Panero F, Costa G, CavalloPerin P, et al. Direct costs in diabetic and non diabetic people: the population-based Turin study, Italy. Nutr Metab Cardiovasc Dis NMCD. 2012;22:684-90.

71. Norlund A, Apelqvist J, Bitzén PO, Nyberg P, Scherstén B. Cost of illness of adult diabetes mellitus underestimated if comorbidity is not considered. J Intern Med. 2001;250:57-65.

72. Wiréhn A-B, Andersson A, Ostgren CJ, Carstensen J. Agespecific direct healthcare costs attributable to diabetes in a Swedish population: a register-based analysis. Diabet Med J Br Diabet Assoc. 2008;25:732-7.
73. Birnbaum H, Leong S, Kabra A. Lifetime medical costs for women: cardiovascular disease, diabetes, and stress urinary incontinence. Women's Health Issues Off Publ Jacobs Institute of Women's Health. 2003;13:204-13.

74. Durden ED, Alemayehu B, Bouchard JR, Chu B-C, Aagren M. Direct health care costs of patients with type 2 diabetes within a privately insured employed population, 2000 and 2005. J Occup Environ Med. 2009;51:1460-5.

75. Rodbard HW, Green AJ, Fox KM, Grandy S. Impact of type 2 diabetes mellitus on prescription medication burden and out-ofpocket healthcare expenses. Diabetes Res Clin Pract. 2010;87: $360-5$.

76. O'Connell JM, Wilson C, Manson SM, Acton KJ. The costs of treating American Indian adults with diabetes within the Indian Health Service. Am J Public Health. 2012;102:301-8.

77. Trogdon JG, Hylands T. Nationally representative medical costs of diabetes by time since diagnosis. Diabetes Care. 2008;31: 2307-11.

78. Ramsey S, Summers KH, Leong SA, Birnbaum HG, Kemner JE, Greenberg P. Productivity and medical costs of diabetes in a large employer population. Diabetes Care. 2002;25:23-9.

79. Van der Linden MW, Plat AW, Erkens JA, Emneus M, Herings RMC. Large impact of antidiabetic drug treatment and hospitalizations on economic burden of diabetes mellitus in The Netherlands during 2000 to 2004. Value in health. 2009;12: 909-14

80. Wang W, McGreevey WP, Fu C, Zhan S, Luan R, Chen W, et al. Type 2 diabetes mellitus in China: a preventable economic burden. Am J Manag Care. 2009;15:593-601.

81. Wang W, Fu CW, Pan CY, Chen W, Zhan S, Luan R, et al. How do type 2 diabetes mellitus-related chronic complications impact direct medical cost in four major cities of urban China? Value Health J Int Soc Pharmacoecon Outcomes Res. 2009;12:923-9.

82. Chan BSW, Tsang MW, Lee VWY, Lee KKC. Cost of type 2 diabetes mellitus in Hong Kong Chinese. Int $\mathrm{J}$ Clin Pharmacol Thera. 2007:45:455-68.

83. Ramachandran A, Ramachandran S, Snehalatha C, Augustine C, Murugesan N, Viswanathan V, et al. Increasing expenditure on health care incurred by diabetic subjects in a developing country: a study from India. Diabetes Care. 2007;30:252-6.

84. Javanbakht M, Baradaran HR, Mashayekhi A, Haghdoost AA, Khamseh ME, Kharazmi E, et al. Cost-of-illness analysis of type 2 diabetes mellitus in Iran. PloS One. 2011;6:e26864.

85. Khowaja LA, Khuwaja AK, Cosgrove P. Cost of diabetes care in out-patient clinics of Karachi, Pakistan. BMC Health Serv Res. 2007;7:189.

86. Biorac N, Jakovljević M, Stefanović D, Perović S, Janković S. Assessment of diabetes mellitus type 2 treatment costs in the Republic of Serbia. Vojnosanit Pregl Mil Med Pharmaceut Rev. 2009;66:271-6.

87. Elrayah-Eliadarous H, Yassin K, Eltom M, Abdelrahman S, Wahlström R, Ostenson C-G. Direct costs for care and glycaemic control in patients with type 2 diabetes in Sudan. Exp Clin Endocrinol Diabetes. 2010;118:220-5.

88. Chatterjee S, Riewpaiboon A, Piyauthakit P, Riewpaiboon W, Boupaijit K, Panpuwong N, et al. Cost of diabetes and its complications in Thailand: a complete picture of economic burden. Health Soc Care Commun. 2011;19:289-98.

89. Al-Maskari F, El-Sadig M, Nagelkerke N. Assessment of the direct medical costs of diabetes mellitus and its complications in the United Arab Emirates. BMC Public Health. 2010;10:679.

90. Druss B, Marcus S, Olfson M. Comparing the national economic burden of five chronic conditions. Health Affairs. 2001;20: 233-41.

91. Tharkar S, Devarajan A, Kumpatla S, Viswanathan V. The socioeconomics of diabetes from a developing country: a 
population based cost of illness study. Diabetes Res Clin Pract. 2010;89:334-40.

92. Wang W, Fu C, Zhuo H, Luo J, Xu B. Factors affecting costs and utilization of type 2 diabetes healthcare: a cross-sectional survey among 15 hospitals in urban China. BMC health services research. 2010;10.

93. Chang K. Comorbidities, quality of life and patients' willingness to pay for a cure for type 2 diabetes in Taiwan. Public Health. 2010;124:284-94.

94. Gyldmark M, Morrison GC. Demand for health care in Denmark: results of a national sample survey using contingent valuation. Soc Sci Med. 2001;53:1023-36.

95. Akobundu E, Ju J, Blatt L, Mullins CD. Cost-of-illness studies : a review of current methods. Pharmacoeconomics. 2006;24:869-90.

96. Larg A, Moss JR. Cost-of-illness studies: a guide to critical evaluation. Pharmacoeconomics. 2011;29:653-71.

97. Breton M-C, Guénette L, Amiche MA, Kayibanda J-F, Grégoire J-P, Moisan J. Burden of diabetes on the ability to work: a systematic review. Diabetes Care. 2013;36:740-9.

98. Brown HS, Pagan JA, Bastida E. The impact of diabetes on employment: genetic IVs in a bivariate probit. Health Econ. 2005;14:537-44.

99. Minor T. The effect of diabetes on female labor force decisions: new evidence from the National Health Interview Survey. Health Econ. 2011;20:1468-86.

100. Latif E. The impact of diabetes on employment in Canada. Health Econ. 2009;18:577-89.

101. Lin SJ. Estimating the impact of diabetes on employment in Taiwan. Econ Bull. 2011;31:3089-102.

102. Zhang X, Zhao X, Harris A. Chronic diseases and labour force participation in Australia. J Health Econ. 2009;28:91-108.

103. Harris A. Diabetes, cardiovascular disease and labour force participation in Australia: an endogenous multivariate probit analysis of clinical prevalence data. Econ Record. 2009;85:472-84.

104. Minor T. An investigation into the effect of type I and type II diabetes duration on employment and wages. Econ Hum Biol. 2013;11:534-44.

105. Bastida E, Pagán JA. The impact of diabetes on adult employment and earnings of Mexican Americans: findings from a community based study. Health Econ. 2002;11:403-13.

106. Liu X, Zhu C. Will knowing diabetes affect labor income? Evidence from a natural experiment. Econ Lett. 2014;124:74-8.

107. Holmes J, Gear E, Bottomley J, Gillam S, Murphy M, Williams R. Do people with type 2 diabetes and their carers lose income? (T2ARDIS-4). Health Policy. 2003;64:291-6.

108. Vijan S, Hayward RA, Langa KM. The impact of diabetes on workforce participation: results from a national household sample. Health Serv Res. 2004;39:1653-69.

109. Ng YC, Philip J, Johnson JA. Productivity losses associated with diabetes in the U.S. Diabetes Care. 2001;24:257-61.

110. Brown IIIHS, Perez A, Yarnell LM, Pagan JA, Hanis CL, FischerHoch SP, et al. Diabetes and employment productivity: does diabetes management matter? Am J Manag Care. 2011;17:569-76.

111. Zhao F-L, Xie F, Hu H, Li S-C. Transferability of indirect cost of chronic disease: a systematic review and meta-analysis. Pharmacoeconomics. 2013;31:501-8.

112. Cameron A, Ewen M, Ross-Degnan D, Ball D, Laing R. Medicine prices, availability, and affordability in 36 developing and middleincome countries: a secondary analysis. Lancet. 2009;373:240-9.

113. Cameron A, Roubos I, Ewen M, Mantel-Teeuwisse AK, Leufkens HGM, Laing RO. Differences in the availability of medicines for chronic and acute conditions in the public and private sectors of developing countries. Bull World Health Organ. 2011;89:412-21.

114. Squires DA. Explaining high health care spending in the United States: an international comparison of supply, utilization, prices, and quality. New York: The Commonwealth Fund; 2012;10: $1-14$.

115. Lorenzoni L, Belloni A, Sassi F. Health-care expenditure and health policy in the USA versus other high-spending OECD countries. Lancet. 2014;384:83-92.

116. Cawley J, Meyerhoefer C. The medical care costs of obesity: an instrumental variables approach. J Health Econ. 2012;31: 219-30.

117. Seuring T, Goryakin Y, Suhrcke M. The impact of diabetes on employment in Mexico. CHE Research Paper. York, UK; 2014.

118. Craig P, Cooper C, Gunnell D, Haw S, Lawson K, Macintyre S, et al. Using natural experiments to evaluate population health interventions: new Medical Research Council guidance. J Epidemiol Commun Health. 2012;66:1182-6.

119. Antonakis J, Bendahan S, Jacquart P, Lalive R, Day DV. Causality and endogeneity: problems and solutions. Oxford: The Oxford Handbook of Leadership and Organizations; 2012.

120. Herder C, Roden M. Genetics of type 2 diabetes: pathophysiologic and clinical relevance. Eur J Clin Investig. 2011;41: 679-92.

121. Hemminki K, Li X, Sundquist K, Sundquist J. Familial risks for type 2 diabetes in Sweden. Diabetes Care. 2010;33:293-7.

122. The Interact Consortium. The link between family history and risk of type 2 diabetes is not explained by anthropometric, lifestyle or genetic risk factors: the EPIC-InterAct study. Diabetologia. 2013;56:60-9.

123. Chiburis RC, Das J, Lokshin M. A practical comparison of the bivariate probit and linear IV estimators. Econ Lett. 2012;117: $762-6$.

124. Kraut A, Walld R, Tate R, Mustard C. Impact of diabetes on employment and income in Manitoba, Canada. Diabetes Care. 2001;24:64-8.

125. Alavinia SM, Burdorf A. Unemployment and retirement and illhealth: a cross-sectional analysis across European countries. Int Arch Occup Environ Health. 2008;82:39-45.

126. Tunceli K, Bradley CJ, Nerenz D, Williams LK, Pladevall M, Elston Lafata J. The impact of diabetes on employment and work productivity. Diabetes Care. 2005;28:2662-7.

127. Tunceli K, Zeng H, Habib ZA, Williams LK. Long-term projections for diabetes-related work loss and limitations among U.S. adults. Diabetes Res Clin Pract. 2009;83:e23-5.

128. Valdmanis V, Smith DW, Page MR. Productivity and economic burden associated with diabetes. Am J Public Health. 2001;91: 129-30.

129. Herquelot E, Guéguen A, Bonenfant S, Dray-Spira R. Impact of diabetes on work cessation: data from the GAZEL cohort study. Diabetes Care. 2011;34:1344-9.

130. Leijten FRM, van den Heuvel SG, Ybema JF, van der Beek AJ, Robroek SJW, Burdorf A. The influence of chronic health problems on work ability and productivity at work: a longitudinal study among older employees. Scandinavian journal of work, environment \& health. 2014;40:473-82

131. Collins JJ, Baase CM, Sharda CE, Ozminkowski RJ, Nicholson $\mathrm{S}$, Billotti GM, et al. The assessment of chronic health conditions on work performance, absence, and total economic impact for employers. J Occup Environ Med. 2005;47:547-57.

132. Lenneman J, Schwartz S, Giuseffi DL, Wang C. Productivity and health: an application of three perspectives to measuring productivity. J Occup Environ Med/Am Coll Occup Environ Med. 2011;53:55-61.

133. Brown HS, Estrada JK, Hazarika G, Bastida E. Diabetes and the labor market: the community-wide economic cost in the Lower Rio Grande Valley. Diabetes Care. 2005;28:2945-7.

134. Kahn M. Health and labor market performance: the case of diabetes. Journal of Labor Economics. 1998;16:878-99. 